\title{
Recent advances in the syntheses of anthracene derivatives
}

\author{
Giovanni S. Baviera ${ }^{\ddagger}$ and Paulo M. Donate ${ }^{*}, \ddagger$
}

\author{
Review \\ Address: \\ Departamento de Química, Faculdade de Filosofia, Ciências e Letras \\ de Ribeirão Preto, Universidade de São Paulo, 14040-091, Ribeirão \\ Preto, SP, Brazil \\ Email: \\ Paulo M. Donate* - pmdonate@usp.br \\ * Corresponding author $\ddagger$ Equal contributors \\ Keywords: \\ anthracenes; anthraquinones; Friedel-Crafts cyclization; \\ intramolecular cyclization; metal-catalyzed
}

Beilstein J. Org. Chem. 2021, 17, 2028-2050.

https://doi.org/10.3762/bjoc.17.131

Received: 19 May 2021

Accepted: 30 July 2021

Published: 10 August 2021

Associate Editor: H. Ritter

(C) 2021 Baviera and Donate; licensee Beilstein-Institut. License and terms: see end of document.

\begin{abstract}
Anthracene and anthracene derivatives have been extensively studied over the years because of their interesting photophysical, photochemical, and biological properties. They are currently the subject of research in several areas, which investigate their use in the biological field and their application in OLEDs, OFETs, polymeric materials, solar cells, and many other organic materials. Their synthesis remains challenging, but some important preparative methods have been reported, especially in the last decade. This review presents an update of the recent strategies that have been employed to prepare anthracene derivatives. It encompasses papers published over the last twelve years (2008-2020) and focuses on direct and indirect methods to construct anthracene and anthraquinone frameworks.
\end{abstract}

\section{Introduction}

Anthracene is an important aromatic hydrocarbon consisting of three linearly fused benzene rings. Because of their extended aromatic and conjugated $\pi$-system, anthracene derivatives possess interesting photochemical and photophysical properties [1-3], as well as gelling ability [4]. These important properties make them relevant for the development and application of several organic materials, such as organic light-emitting diodes (OLEDs) [5], organic field-effect transistors (OFETs) [6], polymeric materials [7], and other kinds of materials [8-10]. For example, OLEDs fabricated with 9,10-diphenylanthracene derivatives 1 and 2 are blue light emitters [11,12], the 2,2'- bianthracene derivative 3 provides a green and fluorescent OLED [13], 2,2'-bianthracenyl (4) has been employed as an organic semiconductor in an OFET device [14], and di-nalkoxyanthracenes have gelling properties with diverse solvents, mainly alkanes and alcohols [4]. Furthermore, anthracene derivatives display useful biological activities; for instance, the anthraquinone derivatives $\mathbf{5}$ and $\mathbf{6}$ exert antimicrobial and antiinflammatory activity, respectively (Figure 1) [15,16].

Despite some difficulties and limitations, a number of synthetic methods for preparing anthracene derivatives has been reported 


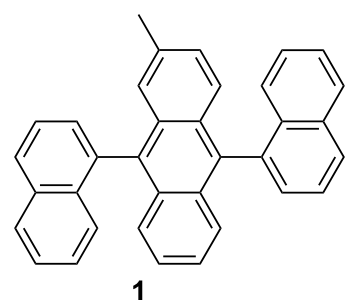

OLED application

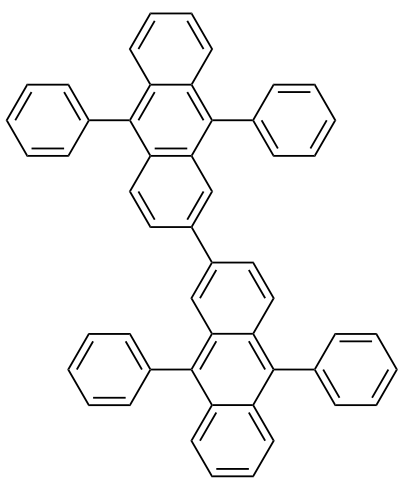

3

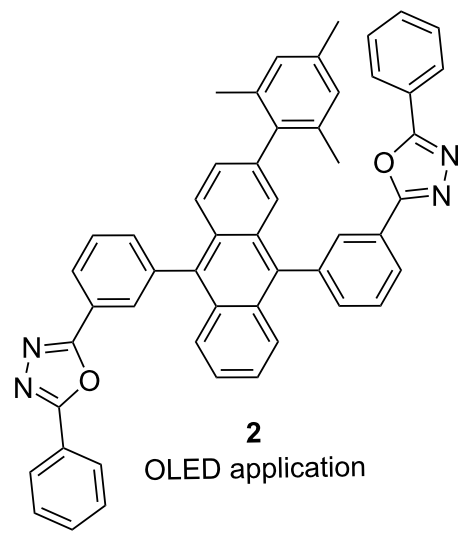<smiles>c1ccc2cc3cc(-c4ccc5cc6ccccc6cc5c4)ccc3cc2c1</smiles>

4

OFET application<smiles>COC1c2c(CC=C(C)C)c(C)cc(O)c2C(=O)c2c(O)cc3c(c21)CC(C(C)(C)O)O3</smiles>

antimicrobial activity<smiles>[R]c1ccc([R1])c2c1C(=O)c1ccccc1C2=O</smiles>

6

$\mathrm{R}^{1}=\mathrm{NH}\left(\mathrm{CH}_{2}\right)_{2} \mathrm{CHOH}\left(\mathrm{CH}_{2}\right)_{9} \mathrm{CH}_{3}$ anti-inflammatory activity

OLED application

Figure 1: Examples of anthracene derivatives and their applications.

over the years. The most familiar methods to obtain substituted anthracenes include Friedel-Crafts reactions [17], Elbs reaction [18], aromatic cyclodehydration [19,20], Bradsher-type reactions from diarylmethanes [21-23], and, more recently, metalcatalyzed reactions with alkynes [24,25]. Numerous synthetic routes have also been reported for the synthesis of anthraquinones [26-29]. On the other hand, preparative methods for dibenzo $[a, h]$ anthracene derivatives are less common, mainly relying on the cyclization of the corresponding lactone derivative followed by sequential modifications [30], photocyclization of divinylterphenyl derivatives [31], tandem radical cyclization of (Z,Z)-1,4-bis(2-iodostyryl)benzene derivatives [32] and ring-closing olefin metathesis of tetravinylterphenyls [33] as the best-known synthetic routes.

Herein, we have classified the synthetic methods into three general categories: synthesis of substituted anthracene frameworks, synthesis of benzanthracene and dibenzanthracene derivatives, and synthesis of anthraquinone derivatives. We will focus on the construction of the anthracene and anthraquinone frameworks published in the last twelve years (2008-2020); methods for simple modifications of the anthracene and anthraquinone rings will be excluded. To the best of our knowledge, this is the first review involving the synthesis of anthracene derivatives spanning this period.

\section{Review}

\section{Synthesis of substituted anthracene} frameworks

\section{Metal-catalyzed reactions with alkynes}

Metal-catalyzed reactions with alkynes have gained attention in the last years and have provided new methodologies to prepare anthracene derivatives. In 2009, Miura and co-workers were the first to obtain substituted anthracenes selectively by homologations with monofunctionalized naphthyl substrates. These authors demonstrated that the rhodium-catalyzed oxidative 1:2 coupling reactions of arylboronic acids 7 with alkyne $\mathbf{8}$ occurred in the presence of a copper-air oxidant, to give the corresponding 1,2,3,4-tetrasubtituted anthracene derivatives 9a and $9 \mathbf{b}$ (Scheme 1) [34]. Although the scope of the reaction was broader for 1,2,3,4-substituted naphthalenes, the authors developed a potentially applicable methodology to synthesize substituted anthracenes and other polysubstituted fused aromatic compounds.

A few years later, Bao et al. employed a similar approach to synthesize substituted anthracenes by the regioselective oxidative benzannulation of 1-adamantyl-1-naphthylamines 10 with internal alkynes 11 (Scheme 2) [35]. To the best of our knowledge, this was the first successful example of rhodium-cata- 
2009, Miura [34]<smiles>[R]c1ccc2cc(Br)ccc2c1</smiles>

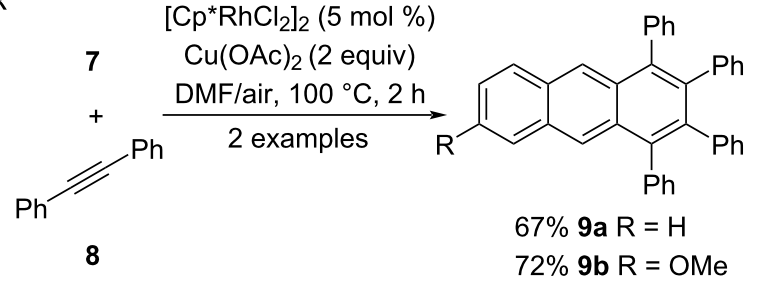

Scheme 1: Rhodium-catalyzed oxidative coupling reactions of arylboronic acids with internal alkynes.

lyzed benzannulation reactions of $\mathrm{N}$-adamantyl-1-naphthylamines. Reactions of $\mathbf{1 0}$ with internal alkynes $\mathbf{1 1}$ bearing an electron-donating or electron-withdrawing group on the benzene ring resulted in the corresponding substituted anthracenes $\mathbf{1 2}$ in moderate to good yields (see the representative examples 12a-g). The same authors also investigated the applicability of reacting internal and asymmetric alkynes with heterocyclic compounds and obtained reasonable to satisfactory results (examples $\mathbf{1 2 h}-\mathbf{k}$ ) [35]. $\mathrm{Cu}(\mathrm{OAc})_{2}$ proved to be an essential oxidant for the success of both the Miura and the Bao methodologies [34,35].

In 2013, Ye and co-workers reported a concise method to synthesize substituted anthracenes $\mathbf{1 4}$ through a gold-catalyzed cyclization of $o$-alkynyldiarylmethanes $\mathbf{1 3}$ (Scheme 3) [36]. The scope of this reaction consisted of 21 examples in good yields (58-80\%). Interestingly, the authors described that the F, Br, and $\mathrm{Me}$ functionalities and even the acid-sensitive OAc group on the aromatic ring were well tolerated during the cyclization, affording the corresponding anthracenes $\mathbf{1 4 a}-\mathbf{d}$. The authors expanded the scope of the reaction to internal alkyne substrates and obtained the corresponding substituted anthracenes. The most representative examples included compounds $\mathbf{1 4} \mathbf{e}-\mathbf{h}$ [36]. In 2015, Lee and co-workers reported a similar approach. They published the synthesis of substituted 9-methylanthracenes $\mathbf{1 4}$ by cyclization of $o$-alkynyldiarylmethanes $\mathbf{1 3}$ in the presence of a bismuth catalyst. The scope of this reaction consisted of 12 examples in good yields (46-86\%). They showed that the introduction of highly electronegative halides, such as fluorine or chlorine, on the phenyl ring afforded the substituted 9-methylanthracenes in lower yields. In addition, the method proposed by Lee and co-workers presented advantages that included shorter reaction times and milder reaction conditions [37].

The direct synthesis of anthracene derivatives is rare and most methods usually involve more than one reaction step. For exam-
2016, Bao [35]
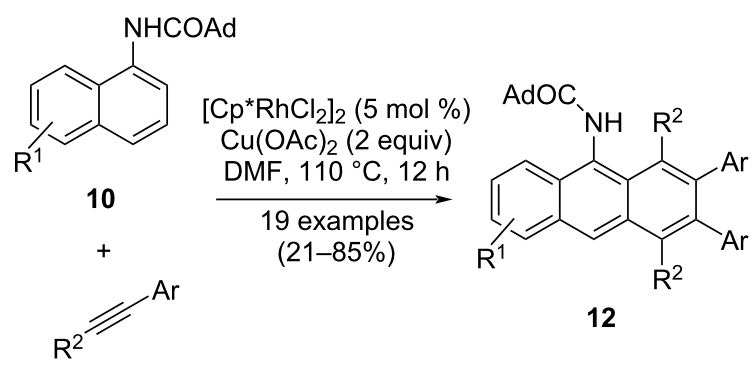

12

11

selected examples<smiles>[R]c1ccc(-c2c(-c3ccc([R])cc3)c(-c3ccc([R])cc3)c3c(NC(=O)[O-])c4cccc([R])c4cc3c2-c2ccc([R])cc2)cc1</smiles>

$56 \% 12 \mathrm{a} R=\mathrm{Me}, \mathrm{R}^{1}=\mathrm{H}$

$60 \% 12 b \mathrm{R}=\mathrm{OMe}, \mathrm{R}^{1}=\mathrm{H}$

$85 \% 12 \mathrm{c} \mathrm{R}=\mathrm{H}, \mathrm{R}^{1}=\mathrm{OMe}$ $60 \% 12 \mathrm{~d} R=\mathrm{H}, \mathrm{R}^{1}=\mathrm{Br}$<smiles>[R]c1ccc(-c2c3cc4ccccc4c(-c4ccc([R])cc4)c(NC(=O)OCc4ccccc4)c-3c(-c3ccc([R])cc3)c2-c2ccc([R])cc2)cc1</smiles>

$50 \% 12 \mathrm{e} R=\mathrm{F}$ $69 \% 12 f \mathrm{R}=\mathrm{Cl}$ $71 \% 12 \mathrm{~g} \mathrm{R}=\mathrm{Br}$<smiles>[R]c1c(-c2ccccc2)c(-c2ccccc2)c([R])c2c(NC(C)=O)c3ccccc3cc12</smiles>

$56 \% 12 \mathrm{~h} \mathrm{R} \mathrm{R}^{2}=\mathrm{Me}$ $41 \% 12 \mathbf{i} R^{2}=\mathrm{Et}$ $48 \%$ 12j $R^{2}=\operatorname{Pr}$<smiles>CC(=O)Nc1c2ccccc2cc2c(-c3cccs3)c(-c3cccs3)c(-c3cccs3)c(-c3cccs3)c12</smiles>

$21 \% 12 k$

Scheme 2: Rhodium-catalyzed oxidative benzannulation reactions of 1-adamantoyl-1-naphthylamines with internal alkynes.

ple, in 2008, Deiters and co-workers described an efficient twostep route to prepare substituted anthracenes and azaanthracenes via microwave-assisted $[2+2+2]$ cyclotrimerization reactions in the presence of nickel and cobalt catalysts [38]. First, they employed diyne $\mathbf{1 5}$ in the reaction with a series of alkynes (16) or nitriles (17) bearing a variety of functional groups including alkyl and alkene chains, hydroxy groups, and benzene and pyridine rings, to achieve the corresponding cyclotrimerization products 18 or 19 (Scheme 4). The subsequent DDQ oxidation step yielded anthracenes 20 or azaanthracenes $\mathbf{2 1}$ in good yields (see the representative examples 20a-d and 21a-d) [38]. 
<smiles>[R]C#Cc1ccccc1C([R])c1ccc(C)cc1</smiles>

13

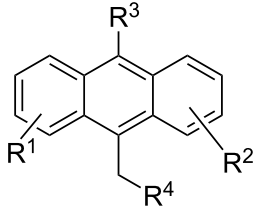

14

\begin{tabular}{c:c}
\hline 2013, Ye [36] & 2015, Lee [37] \\
$\mathrm{R}^{1}=\mathrm{H}, \mathrm{Br}, \mathrm{F}$ or Me & $\mathrm{R}^{1}=\mathrm{H}, \mathrm{F}$ or Me \\
$\mathrm{R}^{2}=\mathrm{H}, \mathrm{F}, \mathrm{Me}$, OMe or OAc & $\mathrm{R}^{2}=\mathrm{H}, \mathrm{F}, \mathrm{Cl}, \mathrm{Me}$ or OMe \\
$\mathrm{R}^{3}=\mathrm{H}$, alkyl or aryl & $\mathrm{R}^{3}, \mathrm{R}^{4}=\mathrm{H}$ \\
$\mathrm{R}^{4}=\mathrm{H}$, alkyl, aryl or ester & \\
& \\
$\mathrm{Et}_{3} \mathrm{PAuNTf} \mathrm{P}_{2}(5 \mathrm{~mol} \%)$ & $\mathrm{Bi}(\mathrm{OTf})_{3}(5 \mathrm{~mol} \%)$ \\
$\mathrm{HNTf}_{2}(0.5$ equiv) & $\mathrm{TFA}(1$ equiv) \\
$\mathrm{DCE}, 80^{\circ} \mathrm{C}, 5 \mathrm{~h}$ & $\mathrm{DCE}, 60^{\circ} \mathrm{C}, 0,5 \mathrm{~h}$ \\
21 examples & 12 examples \\
$(58-80 \%)$ & $(46-86 \%)$ \\
\hline
\end{tabular}

selected examples $(2013, \mathrm{Ye})$ [36]<smiles>[R1]c1ccc2c(C)c3ccccc3cc2c1</smiles>

$63 \% 14 a R^{1}=F$ $68 \% 14 b R^{1}=B r$<smiles>[R]Cc1c2ccccc2cc2ccccc12</smiles>

$71 \% 14$ e $\mathrm{R}^{4}=\mathrm{Ph}$ $72 \% 14 f R^{4}=\mathrm{CO}_{2} \mathrm{Et}$<smiles>[R1]c1cc([R7])c2cc3ccccc3c(C)c2c1</smiles>

$62 \% 14 c \mathrm{R}^{1}=\mathrm{H}, \mathrm{R}^{1}=\mathrm{Me}$ $63 \% 14 d R^{1}=O A c, R^{1}=H$<smiles>[R19]c1c2ccccc2cc2ccccc12</smiles>

$80 \% 14 \mathrm{~g} \mathrm{R}^{4}=\mathrm{OH}, n=3$ $65 \% 14 \mathrm{~h} \mathrm{R} \mathrm{R}^{4}=$ OTs, $n=4$
Scheme 3: Gold/bismuth-catalyzed cyclization of $o$-alkynyldiarylmethanes.

Recently, in a related approach, Bunz, Freudenberg, and co-workers described a useful route to obtain 2,3- and 2,3,6,7-halogenated anthracenes $\mathbf{2 6}$ by using $\mathrm{CpCo}(\mathrm{CO})_{2}$ as catalyst (Scheme 5) [39]. This synthesis started with a cobaltcatalyzed cyclotrimerization of previously prepared bis(propargyl)benzenes 22 and bis(trimethylsilyl)acetylene (23), affording the TMS-substituted cyclotrimerization products $\mathbf{2 4}$. Next, the key step was introducing chlorine, bromine, or iodine substituents by halodesilylation of $\mathbf{2 4}$. With the halogenated products 25 in hands, the authors employed DDQ in the oxidation/aromatization step, to obtain the di- and tetrahaloanthracenes 26 in good yields (61-85\%) [39]. This methodology was notable for being an alternative method to synthesize 2,3,6,7-halogenated anthracene derivatives, which are difficult to obtain.

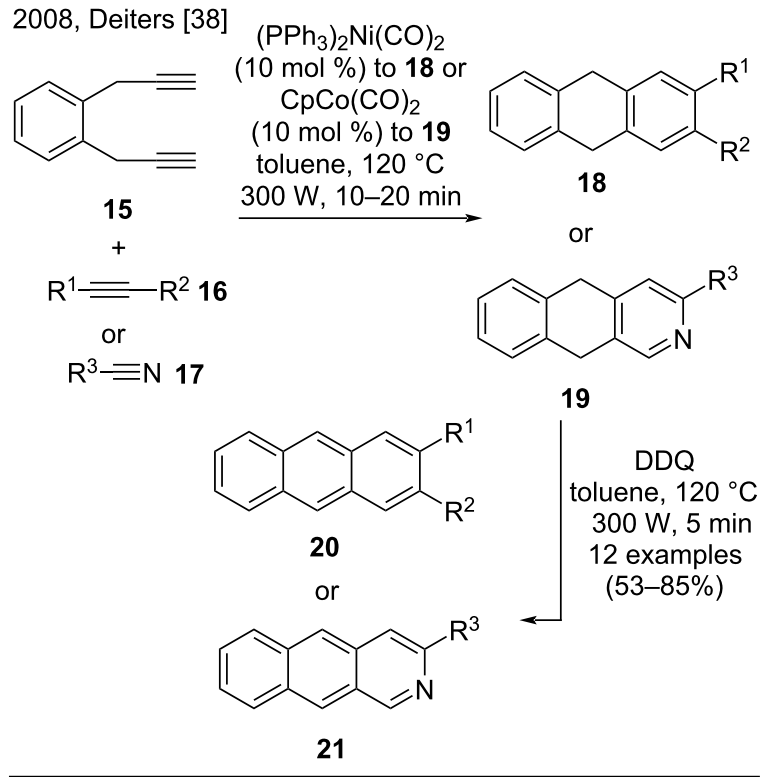

selected examples<smiles>C/C=C\C(Br)=C/C</smiles><smiles></smiles><smiles>CC=C(/C=C\C)/C=C\CC(C)(C)C</smiles>

$70 \% 20 a$

$78 \% 20 b$

$79 \%$ 20c

$74 \% 20 d$<smiles>C/C=C\C(C)=N/C</smiles><smiles>C/C=C\N=C/C</smiles><smiles>C=Cc1cccnc1</smiles><smiles>c1ccc(-c2ccccn2)cc1</smiles>

$75 \% 21 a$

$85 \%$ 21b

$80 \% 21 \mathrm{c}$

$84 \% 21 d$

Scheme 4: $[2+2+2]$ Cyclotrimerization reactions with alkynes/nitriles in the presence of nickel and cobalt catalysts.

2019, Bunz and Freudenberg [39]

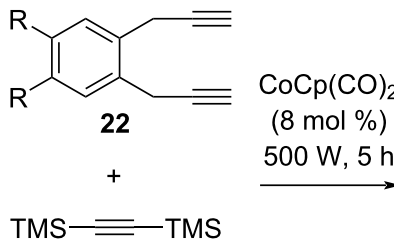

23<smiles>[R]c1cc2cc3cc([R])c([R])cc3cc2cc1[R]</smiles>

$\mathrm{R}=\mathrm{H}, \mathrm{Cl}$ or $\mathrm{Br}$

$\mathrm{X}=\mathrm{Cl}, \mathrm{Br}$ or I

Scheme 5: Cobalt-catalyzed [2 $+2+2]$ cyclotrimerization reactions with bis(trimethylsilyl)acetylene (23). 
In 2010, Okamoto et al. published a three-step procedure to synthesize substituted anthracenes, pentaphenes, and trinaphthylenes via a $[2+2+2]$ alkyne-cyclotrimerization reaction catalyzed by a cobalt/zinc reagent [40]. With regard to substituted anthracenes, this method consisted of a $[2+2+2]$ cycloaddition reaction of 1,6-diynes $\mathbf{2 7}$ with 4-aryl-2-butyn-1-ols $\mathbf{2 8}$ (Scheme 6). The authors converted the resulting benzylic alcohols 29 to the corresponding aldehydes by treatment with PCC/ Celite in dichloromethane (DCM). Finally, treatment with a catalytic amount of $\mathrm{CF}_{3} \mathrm{SO}_{3} \mathrm{H}$ provided the corresponding anthracenes 30a-c in good yields (57-75\%) [40].

\section{0, Okamoto [40]}
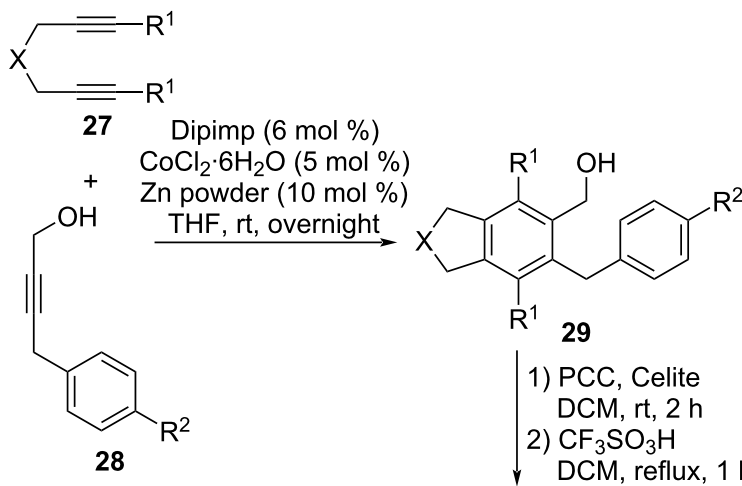

$R^{1} \quad 29$

1) PCC, Celite $\mathrm{DCM}, \mathrm{rt}, 2 \mathrm{~h}$

2) $\mathrm{CF}_{3} \mathrm{SO}_{3} \mathrm{H}$

DCM, reflux, $1 \mathrm{~h}$
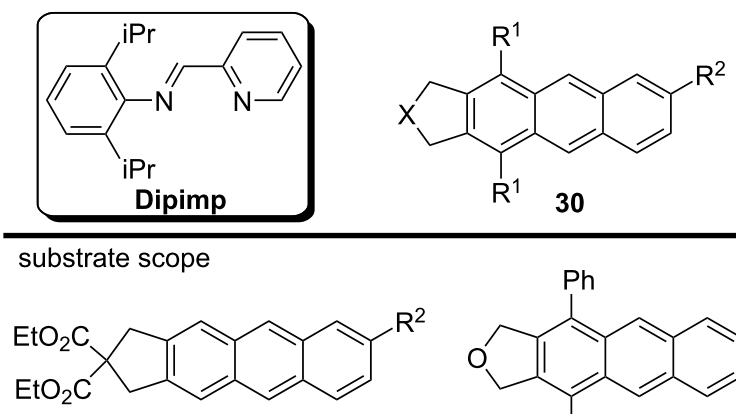

$75 \% 30 a R^{2}=H$ $73 \% 30 \mathrm{~b} \mathrm{R}^{2}=\mathrm{OMe}$

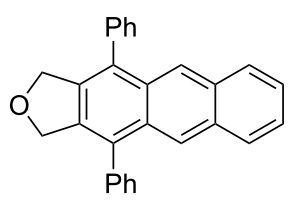

$57 \% 30$ c

Scheme 6: [2+2+2] Alkyne-cyclotrimerization reactions catalyzed by a $\mathrm{CoCl}_{2} \cdot 6 \mathrm{H}_{2} \mathrm{O} / \mathrm{Zn}$ reagent.

\section{Metal-catalyzed $\mathrm{C}-\mathrm{H}$ bond activation}

In 2016, Hong's group developed a synthetic strategy to generate substituted anthracene derivatives 33. The strategy involved a palladium(II)-catalyzed tandem transformation with diphenyl carboxylic acids 31 and acrylates 32 (Scheme 7) [41]. This new methodology involved a carboxyl-directed $\mathrm{C}-\mathrm{H}$ alkenylation, a carboxyl-directed secondary $\mathrm{C}-\mathrm{H}$ activation, an intramolecular C-C-bond formation, and further decarboxylative aromatization. The authors used several diphenyl carboxylic acids bearing electron-donating and electron-withdrawing groups on the aromatic rings to produce the corre-

sponding substituted anthracenes, such as compounds 33a-f, in good yields [41].

$$
\text { selected examples }
$$

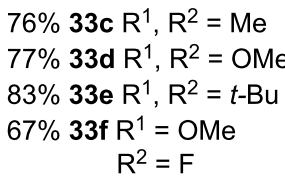

Scheme 7: $\mathrm{Pd}$ (II)-catalyzed $\mathrm{sp}^{3} \mathrm{C}-\mathrm{H}$ alkenylation of diphenyl carboxylic acids with acrylates.

Recently, Kim and co-workers reported a one-pot synthesis of substituted anthracenes $\mathbf{3 7}$ from $o$-tolualdehyde $\mathbf{3 4}$ and aryl iodides 35 via a palladium-catalyzed $\mathrm{C}-\mathrm{H}$ arylation with a silver oxidant (Scheme 8) [42]. During optimization studies, the authors noted that steric and electronic effects strongly affected the cyclization generating the anthracenes. For example, reactions with $o$-tolualdehydes bearing electron-withdrawing substituents showed poor conversions. In addition, by simply changing AgTFA to AgOTf allowed anthracenes $\mathbf{3 7}$ to be ob-

2018, Kim [42]

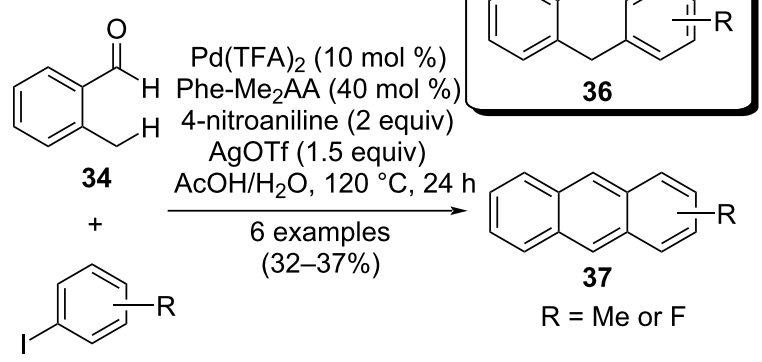

35

Scheme 8: $\mathrm{Pd}(\mathrm{II})$-catalyzed $\mathrm{sp}^{3} \mathrm{C}-\mathrm{H}$ arylation with $\mathrm{o}$-tolualdehydes and aryl iodides. 
tained in low yields (32-37\%) instead of arylated products 36 , the latter of which were more efficiently cyclized [42].

\section{Friedel-Crafts alkylation of arenes with aromatic aldehydes}

The Lewis acid-catalyzed Friedel-Crafts alkylation of electronrich arenes with aromatic aldehydes has proven an efficient and often direct method to prepare anthracene derivatives. Kodomari and co-workers disclosed a convenient synthesis of triarylmethanes and 9,10-diarylanthracenes from reactions of arenes and aromatic aldehydes by using acetyl bromide in the presence of silica gel-supported zinc bromide [43]. The methodology developed by these authors involved using excess of one of the reagents. When the authors employed excess benzaldehyde $(\mathbf{3 9})$ in the reaction with veratrole $(\mathbf{3 8})$, they obtained 9,10-diarylanthracene $\mathbf{4 0}$ in good yield (Scheme 9). On the other hand, the reaction of excess veratrole (38) with benzaldehyde (39) produced triarylmethane $\mathbf{4 1}$. The reaction of $\mathbf{4 1}$ with 4-chlorobenzaldehyde (42) afforded 9,10-diarylanthracene $\mathbf{4 3}$, so the authors concluded that triarylmethane is an intermediate in the reaction with excess benzaldehyde [43].

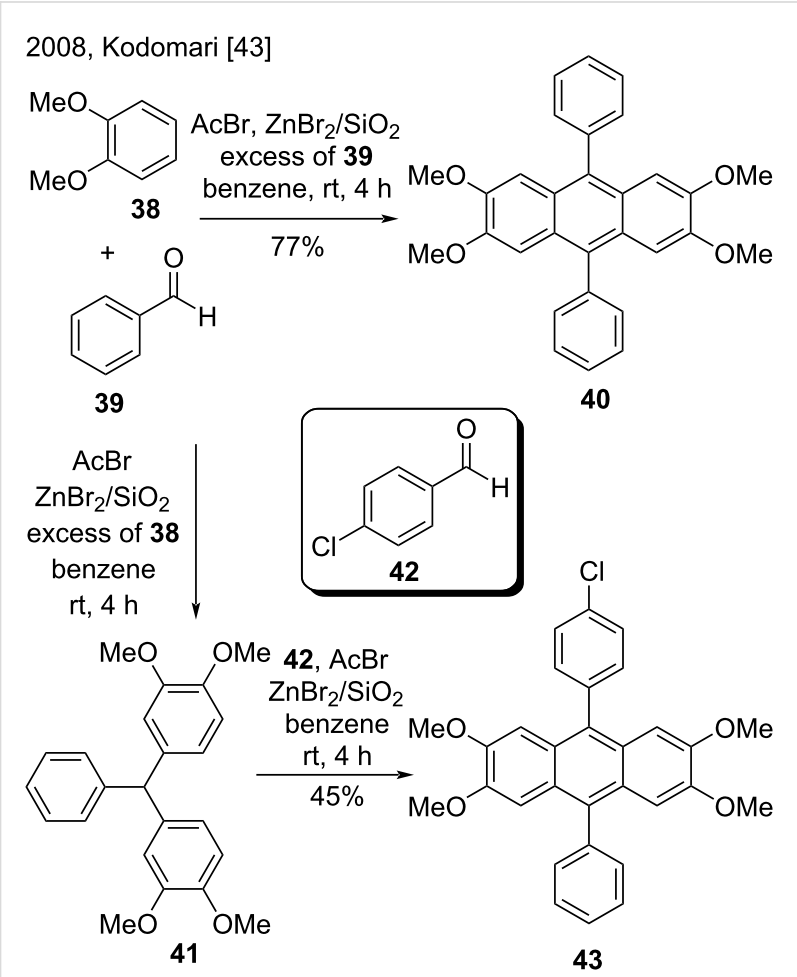

Scheme 9: Alkylation of arenes with aromatic aldehydes in the presence of acetyl bromide and $\mathrm{ZnBr}_{2} / \mathrm{SiO}_{2}$.

In 2009, Olah's group applied $\mathrm{BF}_{3}$ monohydrate as acid catalyst in arene hydroxyalkylation with aromatic aldehydes, to provide triarylmethane, diarylmethylbenzaldehyde, and anthracene derivatives. In this work, the reaction of phthalaldehyde (44) with arenes 45 resulted in anthracene derivatives 46-48 as major products (Scheme 10) [17]. In fact, the authors obtained mixtures of anthracene derivatives, with 9-arylanthracenes $\mathbf{4 7}$ in greater proportion in almost all reactions. On the other hand, the reaction of $\mathbf{4 4}$ with 1,2,3,4-tetramethylbenzene (45a) resulted in tetrametylanthracene 46a in good yield $(80 \%)$. However, the reaction only gave good results with electron-rich arenes [17].

2009, Olah [17]

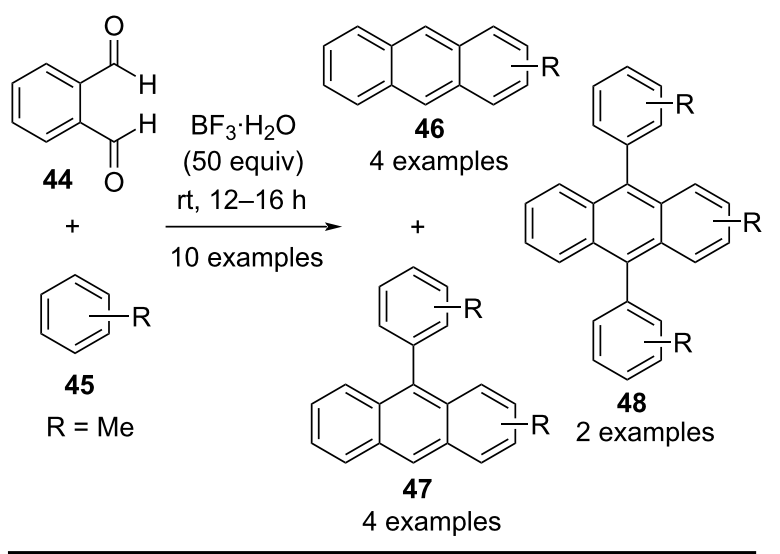<smiles>Cc1ccc(C(C)(C)C)c(C)c1C=O</smiles>

Scheme 10: $\mathrm{BF}_{3} \cdot \mathrm{H}_{2} \mathrm{O}$-catalyzed hydroxyalkylation of arenes with aromatic dialdehyde 44.

In 2016, Mohammadiannejad-Abbasabadi and co-workers unveiled a three-step procedure to synthesize 9,10-disubstituted-anthracenes from bis(dihexyloxyphenyl)arylmethanes or diveratrylmethanes and aromatic acylals [44]. In the first step, reaction between aromatic aldehydes 49 and acetic anhydride (50) promoted by $\mathrm{Bi}(\mathrm{OTf})_{3}$ under solvent-free conditions afforded aromatic acylals 51 (Scheme 11). In the next two steps, the authors added previously prepared triarylmethanes $\mathbf{5 2}$ to the reaction mixture under air atmosphere, and then under oxygen atmosphere. Therefore, an efficient $\mathrm{Bi}(\mathrm{OTf})_{3} / \mathrm{O}_{2}$ system promoted the oxidation/aromatization step, providing the 9,10disubstituted 2,3,6,7-tetraalkoxyanthracenes $\mathbf{5 3}$ in good yields (58-87\%). Additionally, the authors reacted veratrole (38) and phthalaldehyde (44) in the presence of $\mathrm{Bi}(\mathrm{OTf})_{3}$, to obtain the substituted anthracene derivative $\mathbf{5 4}$ in good yield (88\%). Under the same conditions, the reaction of veratrole (38) and isophtha- 
laldehyde afforded only the corresponding triarylmethane in 93\% yield, indicating that this reaction strongly depended on the nature of the aromatic aldehyde [44].

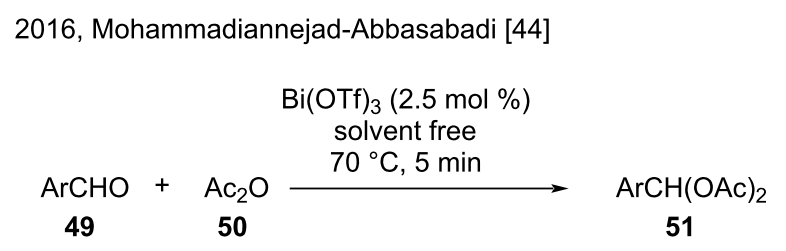<smiles>[R20]Oc1cc2c([R])c3cc(O[R2])c([R2])cc3c([Al])c2cc1[R2]</smiles>

53

$\mathrm{R}^{1}=$ aryl or $\mathrm{Me}$ $\mathrm{R}^{2}=$ Me or hexyl<smiles>COc1ccc(-c2c3ccccc3cc3cc(OC)c(OC)cc23)cc1OC</smiles>

Scheme 11: $\mathrm{Bi}(\mathrm{OTf})_{3}$-promoted Friedel-Crafts alkylation of triarylmethanes and aromatic acylals and of arenes and aromatic aldehydes.

\section{Synthesis of substituted anthracenes from anthraquinones}

An easy and common method to obtain anthracenes is to reduce anthraquinones by using several reagents. An important advantage of this method is that the reactive positions 9 and 10 of anthracene are protected, directing substitution to one of the other rings. By using this kind of methodology, in 2009, Han, Nedeltchev, and Bhowmik reported the facile synthesis of 9,10diacetoxyanthracenes $\mathbf{5 6}$ and 2,6-dialkoxyanthracenes $\mathbf{5 8}$ from the corresponding anthraquinones $\mathbf{5 5}$ and $\mathbf{5 7}$ via a single-step reduction with either zinc/pyridine or zinc/ $\mathrm{NaOH}$ (Scheme 12). The scope of their work consisted of six examples, and they obtained anthracene derivatives in moderate to good yields (50-87\%) [45].
2009, Han, Nedeltchev and Bhowmik [45]<smiles>[R]c1cccc2c1C(=O)c1ccccc1C2=O</smiles>

$\mathrm{Zn}$, acetic anhydride $\underset{\text { pyridine, reflux, } 3 \mathrm{~h}}{4 \text { examples }}$ (65-79\%) $\mathrm{R}=$ alkoxy<smiles>[R]c1cccc2c(OC(C)=O)c3ccccc3c(OC(C)=O)c12</smiles>

$\mathrm{R}=$ alkoxy

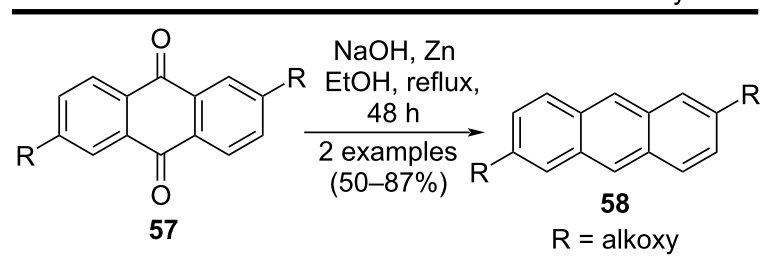

Scheme 12: Reduction of anthraquinones by using $\mathrm{Zn} /$ pyridine or $\mathrm{Zn} / \mathrm{NaOH}$ reductive methods.

In 2014, Yucel and co-workers synthesized 12 novel indenoanthracene derivatives to study their optical, electrochemical, and thermal properties [46]. The authors prepared dialkynyl-substituted indenoanthracenes 61, containing alkyl or bromine substituents, from the corresponding indenoantraquinones $\mathbf{5 9}$ in two steps in good to excellent yields (57-92\%) (Scheme 13). Representative examples included indenoanthracenes 61a-c, bearing aryl groups linked to the alkyne, and indenoanthracenes $\mathbf{6 1 d - f}$, containing tetramethylsilane groups at the terminal alkyne [46].

From commercially available 1,8-dichloroanthraquinone (62) and by using modified Suzuki-Miyaura coupling reaction conditions, Agarwal et al. synthesized a series of 1,8-diarylanthracene derivatives 64 in two steps (Scheme 14) [47]. First, the simple reduction of anthraquinone $\mathbf{6 2}$ employing the wellknown reductive $\mathrm{Zn} / \mathrm{NH}_{3}$ system and $\mathrm{HCl}$ provided 1,8dichloroanthracene (63). A Suzuki-Miyaura coupling reaction in the presence of $\mathrm{Pd}\left(\mathrm{PPh}_{3}\right)_{4}$ as catalyst, was inefficient with the chloro-substituted aryl substrates. However, the use of Pd-PEPPSI-iPr as catalyst solved this problem. By using this catalyst, the authors obtained 1,8-diarylanthracenes $64 \mathbf{a}-\mathbf{f}$ in good yields (52-77\%) from reactions of the corresponding arylboronic acids [47].

In 2016, Pal and co-workers prepared five new substituted anthracene derivatives $\mathbf{6 8}$ containing six alkyl chains (Scheme 15) [48]. The authors synthesized hexahydroxyanthraquinone 65 and modified the functional groups in compound $\mathbf{6 5}$ and its derivative $\mathbf{6 6}$ according to reported methods. Although other methodologies were available, the authors chose to employ lithium aluminum hydride $(\mathrm{LAH})$ to reduce the 
2014, Yucel [46]<smiles>[R]c1ccc2c(c1)C([R1])([R])c1cc3c(cc1-2)C(=O)c1ccccc1C3=O</smiles>

$\mathrm{R}^{3}$

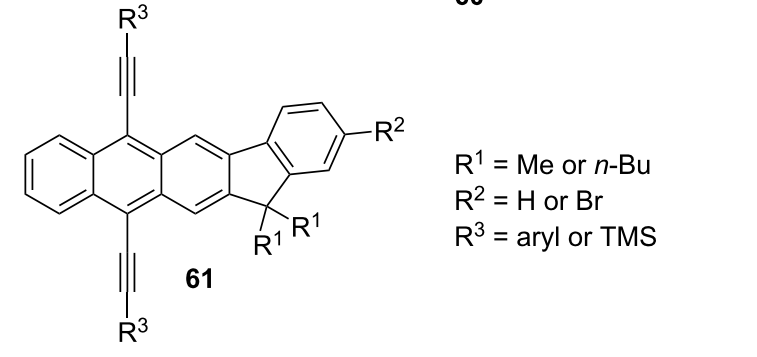

selected examples

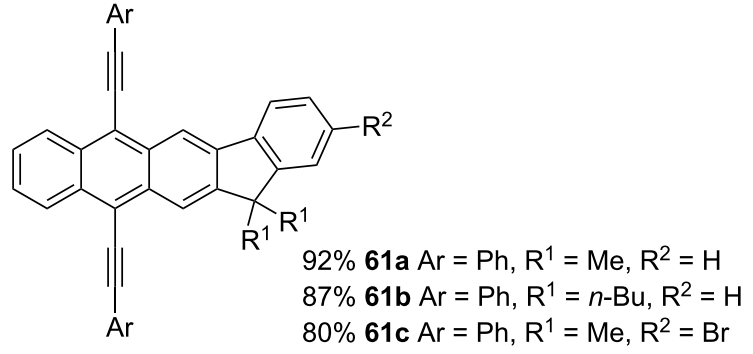

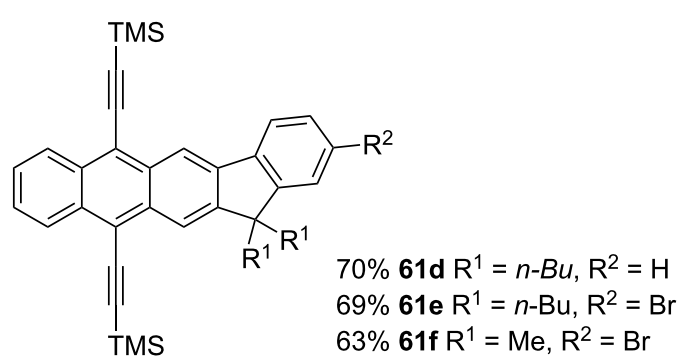

Scheme 13: Two-step route to novel substituted Indenoanthracenes.

substituted anthraquinones $\mathbf{6 7}$ to the corresponding anthracenes 68, to obtain very good yields (81-90\%) [48].

In 2016, Glöcklhofer and co-workers developed a versatile onepot procedure for the direct synthesis of 9,10-dicyanoanthracenes from 9,10-anthraquinones [49]. Despite the challenges presented by the different substrates, a long study of reaction optimization allowed the authors to synthesize 9,10-dicyanoanthracene (70a), 2,6-dibromo- (70b), and 2,6-diiodo-9,10dicyanoanthracene (70c) from the corresponding 9,10anthraquinones 69 in good yields (53-79\%) (Scheme 16) [49].

In 2017, Skalamera and co-workers reported a new synthetic pathway to produce 2,3-disubstituted anthracenes by functionalizing the corresponding anthraquinone and subsequent reduction with $\mathrm{NaBH}_{4}$ [50]. Via a known procedure, the authors con-
2015, Agarwal [47]

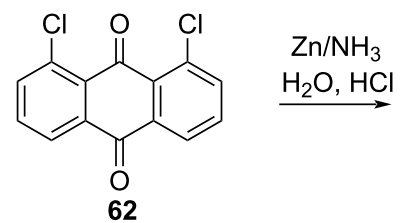<smiles>Clc1cccc2cc3cccc(Cl)c3cc12</smiles>

63

Pd-PEPPSI-iPr (5-7 mol \%) arylboronic acids, $\mathrm{Na}_{2} \mathrm{CO}_{3}$ $80^{\circ} \mathrm{C}, \mathrm{H}_{2} \mathrm{O} /$ toluene/THF 6 examples $(52-70 \%)$<smiles>O=[W](=O)(Oc1ccccc1)c1cccc(Br)c1</smiles>

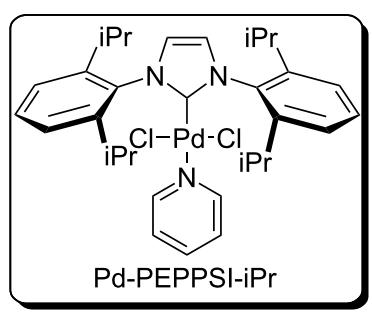

substrate scope

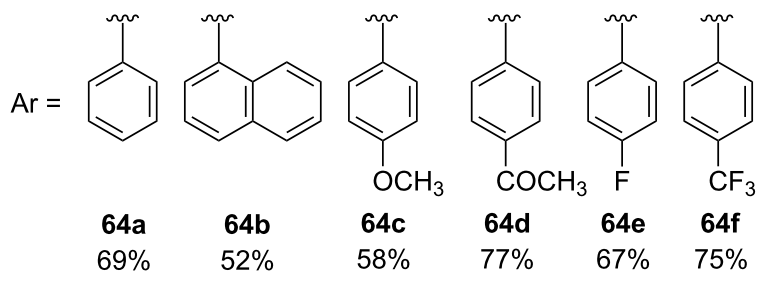

Scheme 14: Synthesis of 1,8-diarylanthracenes through Suzuki-Miyaura coupling reaction in the presence of Pd-PEPPSI-iPr as catalyst.

verted commercially available 2 -aminoanthraquinone (71) to 2-hydroxyanthraquinone (72), followed by bromination that led to a mixture of bromoanthraquinones 73a-c (Scheme 17). According to the authors, many existing methods to reduce anthraquinones 73a and 73b have been tested, but only the onestep method with sodium borohydride in alkaline medium resulted in 2,3-disubstituted anthracene 74a, the precursor of anthracene target 75, in excellent yield (95\%) [50].

\section{Intramolecular cyclization}

Intramolecular cyclization is a broad category that covers several known methodologies for the synthesis of anthracene derivatives. Traditionally, widely used methods include acidcatalyzed Friedel-Crafts intramolecular cyclization and Bradsher-type reactions and their variations [21]. Interestingly, some of the methods already reviewed here could also be included in this category although they are classified in other categories that are also appropriate. 
2016, Pal [48]<smiles>O=C1c2cc(O)c(O)c(O)c2C(=O)c2cc(O)c(O)c(O)c21</smiles>

$\mathrm{R}^{1} \mathrm{Br}, \mathrm{NaOH}$
$\mathrm{DMSO}$
$70^{\circ} \mathrm{C}, 18 \mathrm{~h}$
$\stackrel{\longrightarrow}{\longrightarrow}$<smiles>[R10]Oc1cc2c(c(O)c1[R10])C(=O)c1cc(O[R10])c(O[R10])c(O)c1C2=O</smiles>
$\mathrm{R}^{2} \mathrm{Br}, \mathrm{K}_{2} \mathrm{CO}_{3}$ THF, reflux<smiles>[R10]Oc1cc2c(c([R2])c1O[R17])C(=O)c1cc([R10])c([R2])c([R])c1C2=O</smiles>

$\mathrm{LiAlH}_{4}$ THF, reflux 5 examples $(81-90 \%)$

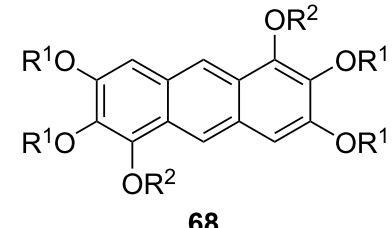

$\mathrm{R}^{1}, \mathrm{R}^{2}=\mathrm{CH}_{3}, \mathrm{C}_{6} \mathrm{H}_{13}$ or $\mathrm{C}_{8} \mathrm{H}_{17}$

Scheme 15: Synthesis of five new substituted anthracenes by using $\mathrm{LAH}$ as reducing agent.

2016, Glöcklhofer [49]<smiles>[R]c1ccc2c(c1)C(=O)c1ccc([R])cc1C2=O</smiles>

$\mathrm{KCN}(0,05$ equiv $)$

DMF, $3 \mathrm{~h}$, rt;

$\mathrm{PBr}_{3}$ (1.20 equiv)

$\mathrm{MeCN}, 3 \mathrm{~h}, 50^{\circ} \mathrm{C}$<smiles>[R]c1ccc2c(C#N)c3cc([R])ccc3c(C#N)c2c1</smiles>

Scheme 16: One-pot procedure to synthesize substituted 9,10-dicyanoanthracenes.

Takai, Kuninobu, and their research group used an indium catalyst to synthesize polycyclic aromatic compounds via a reductive-dehydration intramolecular cycloaromatization [51], which is a Bradsher-type reaction. The authors prepared substituted anthracenes 77, bearing phenyl, methyl, chloro, or methoxy groups, such as $\mathbf{7 7 a - c}$ in excellent yields (94-96\%) by treating the corresponding 2-benzylic aromatic aldehydes/ketones $\mathbf{7 6}$ with a catalytic amount of $\operatorname{In}(\mathrm{OTf})_{3}$ (Scheme 18) [51]. In addition, the authors explored this methodology to obtain polycyclic aza-aromatic compounds. They achieved promising results and obtained the aza-analogue acridine (79) from 2-(phenylamino)benzaldehyde (78) in excellent yield (97\%) [51].

In 2012, Balczewski and co-workers reported a new methodology to synthesize 10-OR-substituted anthracenes 82 via an acid- catalyzed cyclization of $O$-protected ortho-acetal diarylmethanols 81a and 81b as a new type of reactants (Scheme 19) [52]. To carry out the cyclization step, this new methodology employed a diluted aqueous methanolic solution of $\mathrm{HCl}$ at room temperature. This step was based on a modified intramolecular Friedel-Crafts-type cyclization. This was the first report of the same molecule bearing an acid-sensitive acetal and dibenzyl alkoxy groups. The key steps described in the work were protection of the aldehyde group of 6-bromopiperonal (80) by using 1,2-ethanediol or 1,3-propanediol, followed by sequential transformations of the resulting adduct into the protected diarylmethanols 81a and 81b. The scope of the reaction consisted of five examples $(\mathbf{8 2} \mathbf{a}-\mathbf{e})$ that were obtained in moderate yields (30-68\%). According to the authors, the reaction conditions were the mildest ever used in this type of intramolecular cyclization until 2012 [52]. 


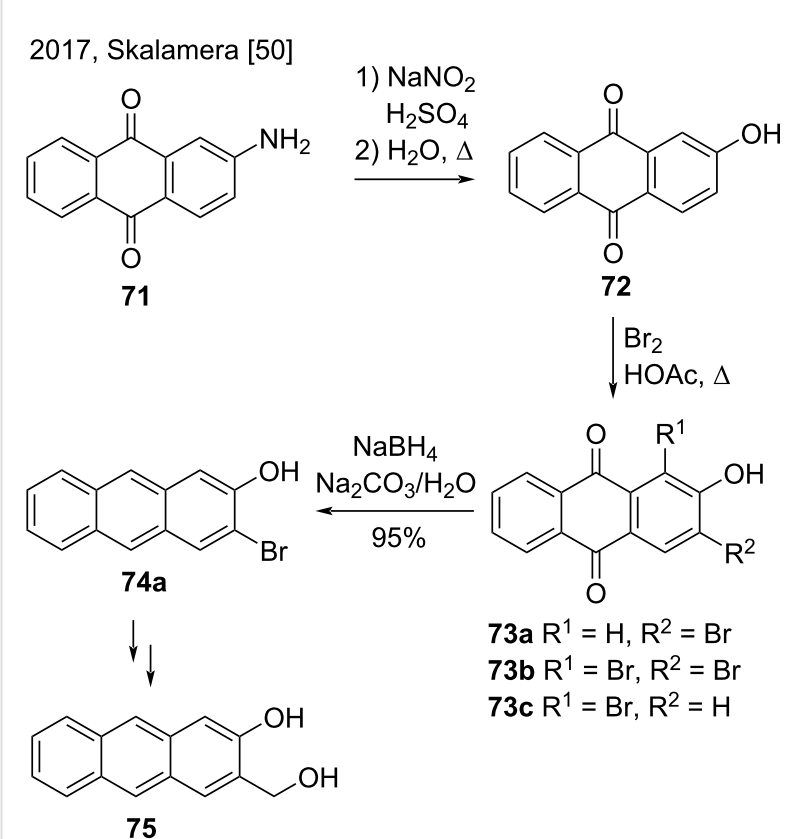

Scheme 17: Reduction of bromoanthraquinones with $\mathrm{NaBH}_{4}$ in alkaline medium.

2011, Takai and Kuninobu [51]<smiles>[R][R]1ccc(Cc2ccccc2C(=O)c2ccccc2)cc1</smiles>

76

$$
\begin{gathered}
\ln (\mathrm{OTf})_{3}(5 \mathrm{~mol} \%) \\
\text { DCE, } 115^{\circ} \mathrm{C} \\
1-24 \mathrm{~h} \\
\underset{9 \text { examples }}{\longrightarrow}
\end{gathered}
$$

$(94-97 \%)$

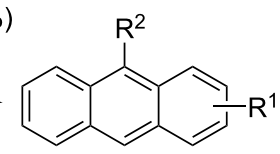

77

$\mathrm{R}^{1}=\mathrm{H}, \mathrm{Me}$, OMe or $\mathrm{Cl}$ $\mathrm{R}^{2}=\mathrm{H}, \mathrm{Me}$ or $\mathrm{Ph}$<smiles>O=Cc1ccccc1Nc1ccccc1</smiles>

78 $\ln (\mathrm{OTf})_{3}(5 \mathrm{~mol} \%)$

DCE, $115^{\circ} \mathrm{C}$
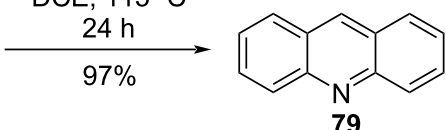

79

selected examples<smiles>c1ccc(-c2c3ccccc3cc3ccccc23)cc1</smiles>

$96 \% 77 a$

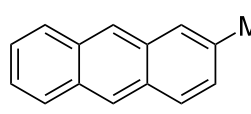

$94 \% 77 b$

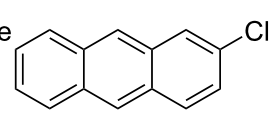

$96 \% 77 \mathrm{c}$
Scheme 18: In(III)-catalyzed reductive-dehydration intramolecular cycloaromatization of 2-benzylic aromatic aldehydes/ketones.

Mohanakrishnan's group has contributed with numerous methodologies for the synthesis of anthracene derivatives, mainly methodologies involving Lewis acid-mediated intramolecular cyclizations. For example, in 2012 they reported an annulation protocol to synthesize anthracene, tetracene, and

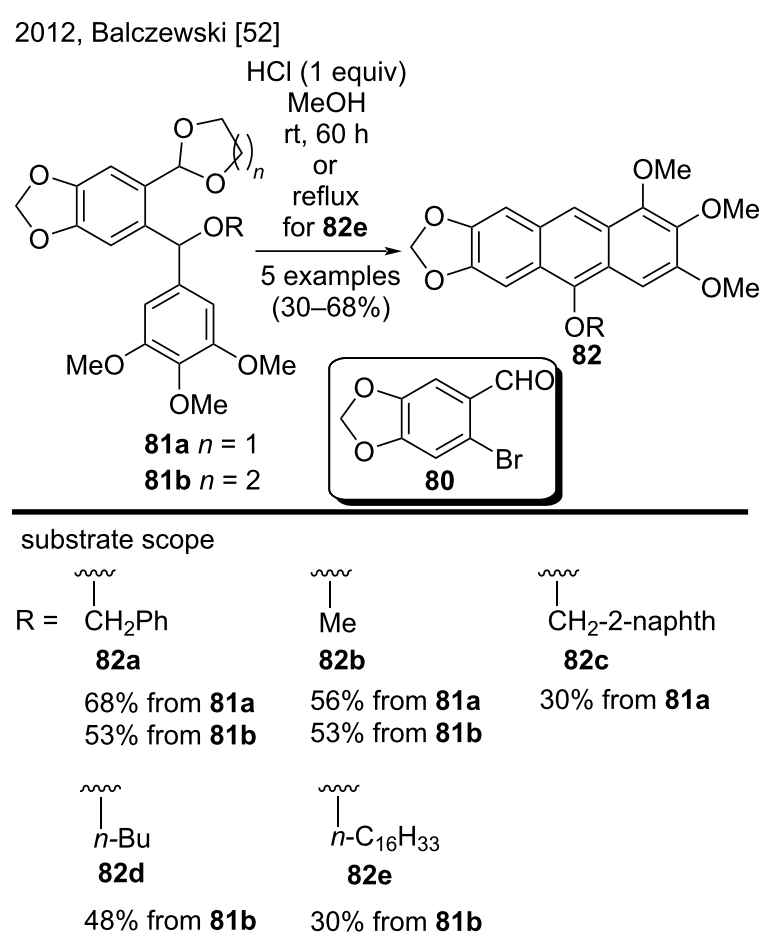

Scheme 19: Acid-catalyzed cyclization of new O-protected orthoacetal diarylmethanols.

naphtho[b]thiophene derivatives via $\mathrm{ZnBr}_{2}$-mediated regioselective annulation of asymmetric 1,2-diarylmethine dipivalates 83a (Scheme 20). On the basis of this methodology, they prepared 37 examples of different types of anthracene derivatives, such as compounds 84a-e, in very good yields (89-94\%) and mild reaction conditions [53].

In a related approach, in 2015, Mohanakrishnan and his group reported the synthesis of anthracene derivatives and other annulated products via the regioselective cyclization of asymmetric 1,2-diarylmethine diol $\mathbf{8 3 b}$ by using a $\mathrm{HBr} / \mathrm{AcOH}$ system (Scheme 20) [54]. They obtained substituted anthracene derivatives in very good yields (71-94\%) and representative examples included 84f-k [54]. By using both methodologies, the authors obtained substituted benzo $[a]$ anthracenes from compounds 83. In 2015, Mohanakrishnan's group also disclosed a Bradsher-type cyclodehydration of substituted 2-arylmethylbenzaldehyde 85a mediated by $\mathrm{BF}_{3} \cdot \mathrm{OEt}_{2}$ (Scheme 21) [55]. By using this methodology, they prepared substituted anthracene derivatives 86 in excellent yields (75-93\%). Impressively, the authors were able to synthesize these compounds in better yields via a two-step procedure involving the cyclization of 2-arylmethylbenzoic acid $\mathbf{8 5} \mathbf{b}$ with triflic acid, followed by a $\mathrm{NaBH}_{4}$-mediated reductive dehydration. Some representative examples included anthracenes 86a-g. For those interested, the cyclodehydration was also extended to 2-(arylmethyl)naph- 


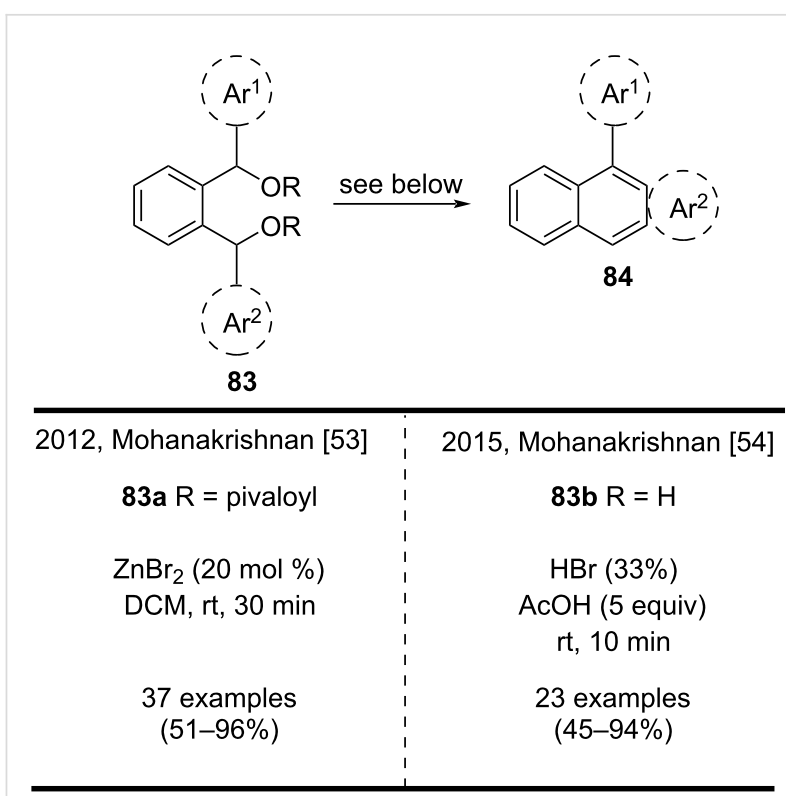

selected examples (2012 and 2015)<smiles>[R]c1ccc2cc3ccccc3c(-c3ccc([R])c([R])c3)c2c1</smiles><smiles>[R]c1cc([R])c2cc3ccccc3c(-c3c([R])ccc4ccccc34)c2c1</smiles>

$\mathrm{R}^{1}=\mathrm{Me}, \mathrm{R}^{2}, \mathrm{R}^{3}=\mathrm{H}$

$94 \% 84 b$

$\mathrm{R}^{1}=\mathrm{OMe}, \mathrm{R}^{2}, \mathrm{R}^{3}=\mathrm{H}$

$94 \% 84 c$

$\mathrm{R}^{1}=\mathrm{Ph}, \mathrm{R}^{2}, \mathrm{R}^{3}=\mathrm{H}$

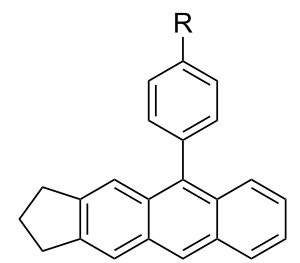

$81 \% 84 f \mathrm{R}=\mathrm{H}$

$92 \% 84 \mathrm{~g} \mathrm{R}=\mathrm{Me}$

$94 \% 84 \mathrm{~h} \mathrm{R}=\mathrm{OMe}$
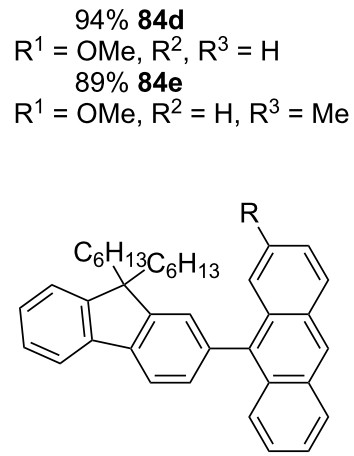

$83 \% 84 i \mathrm{R}=\mathrm{H}$

$73 \% 84 \mathrm{j}=\mathrm{Me}$

$71 \%$ 84k R $=$ OMe

Scheme 20: Lewis acid-mediated regioselective cyclization of asymmetric diarylmethine dipivalates and diarylmethine diols.

thaldehydes and 2-(arylmethyl)naphthoic acids, to produce the corresponding annulated compounds [55].

Recently, Glöcklhofer and co-workers developed a promising method to prepare 2,3,6,7-substituted anthracene derivatives via an intramolecular double ring-closing condensation approach (Scheme 22) [56]. As a demonstration of this new methodology, they synthesized 2,3,6,7-anthracenetetracarbonitrile (90) in a good yield $(84 \%)$ by double intermolecular Wittig reaction of

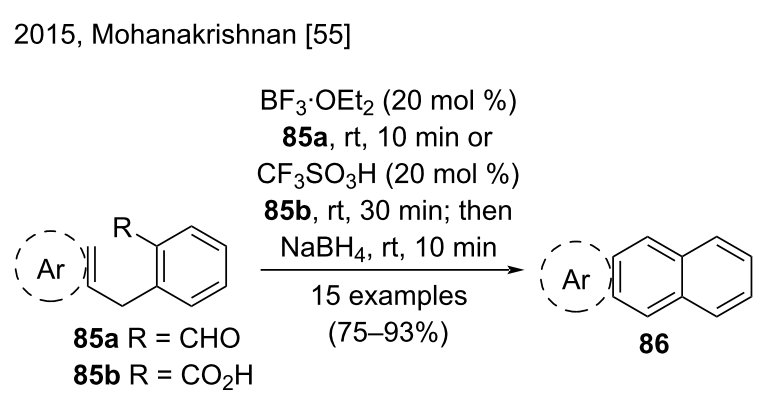

selected examples<smiles>[R]c1cc2cc3ccccc3cc2c([R])c1[R]</smiles>

$92 \% 86 \mathrm{a} \mathrm{R}^{1}, \mathrm{R}^{2}=\mathrm{H}, \mathrm{R}^{3}=\mathrm{Me}$ $87 \% 86 b R^{1}=H, R^{2}, R^{3}=M e$ $87 / 91 \% 86 c R^{1}=H, R^{2}, R^{3}=O M e$ $91 / 92 \% 86 d R^{1}, R^{2}=H, R^{3}=P h$<smiles></smiles>

$86 f$

$92 \%$ from $85 a$ $89 \%$ from $\mathbf{8 5 b}$<smiles>Cc1cc2cc3ccccc3cc2c2ccccc12</smiles>

$89 \%$ from $85 a$ $91 \%$ from $\mathbf{8 5 b}$
Scheme 21: $\mathrm{BF}_{3} \cdot \mathrm{OEt}_{2} / \mathrm{CF}_{3} \mathrm{SO}_{3} \mathrm{H}$-mediated cyclodehydration reactions of 2-(arylmethyl)benzaldehydes and 2-(arylmethyl)benzoic acids.

the protected benzenetetracarbaldehyde $\mathbf{8 7}$ with reagent $\mathbf{8 8}$, followed by deprotection and double ring-closing reaction of intermediate 89; they used a mixture of triflic acid/water in the first step and trimethylamine in the next reaction step [56].

\section{Other procedures}

In 2008, Lin et al. reported a homo-elongation protocol to obtain acene diesters and dinitriles starting from dialdehydes (Scheme 23) [57]. This methodology was based on a Wittig reaction between substituted $[n]$ acene-2,3-dicarbaldehydes 91 and the Wittig reagents 92; DBU was employed to produce the corresponding substituted $[n+1]$ acene-2,3-diethyl diesters 93. Then, in two steps (reduction and Swern oxidation), the authors converted the diesters 93 to the dialdehydes 94 , which could be transformed into the corresponding $[n+2]$ acene-2,3-diethyl diesters 95 by the procedure described above. The scope of the reaction included five examples of substituted anthracene-2,3dicarboxylates bearing $\mathrm{Cl}$ or alkoxy groups (43-86\% yield). Lin et al. also applied the same approach to synthesize acene-2,3dinitriles 96 by using fumaronitrile to produce the Wittig reagents. Despite the limitations, the authors noted that DBU was no longer required in these reactions. The scope of these reactions included five examples of substituted anthracene-2,3dicarbonitriles 96 (40-62\% yield) [57]. 
2020, Glöcklhofer [56]
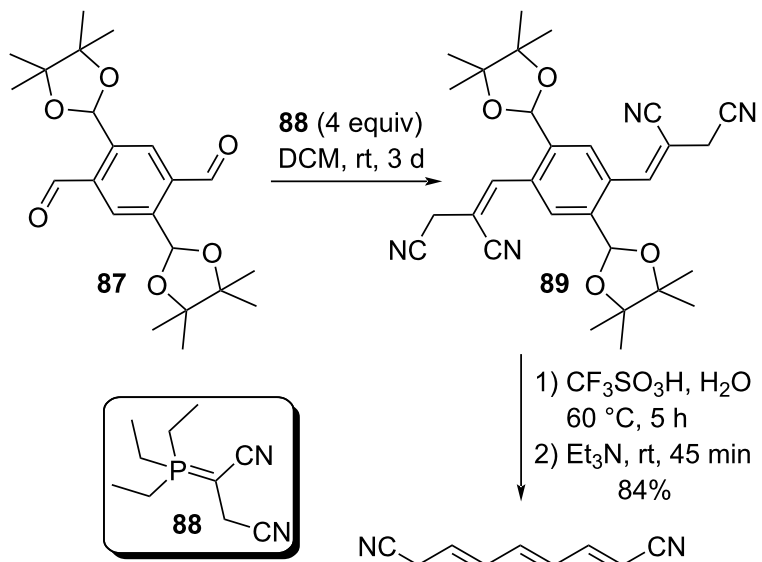

1) $\mathrm{CF}_{3} \mathrm{SO}_{3} \mathrm{H}, \mathrm{H}_{2} \mathrm{O}$ $60{ }^{\circ} \mathrm{C}, 5 \mathrm{~h}$

2) $\mathrm{Et}_{3} \mathrm{~N}, \mathrm{rt}, 45 \mathrm{~min}$ $84 \%$<smiles>N#Cc1cc2cc3cc(C#N)c(C#N)cc3cc2cc1C#N</smiles>

Scheme 22: Synthesis of 2,3,6,7-anthracenetetracarbonitrile (90) by double Wittig reaction followed by deprotection and intramolecular double ring-closing reaction.

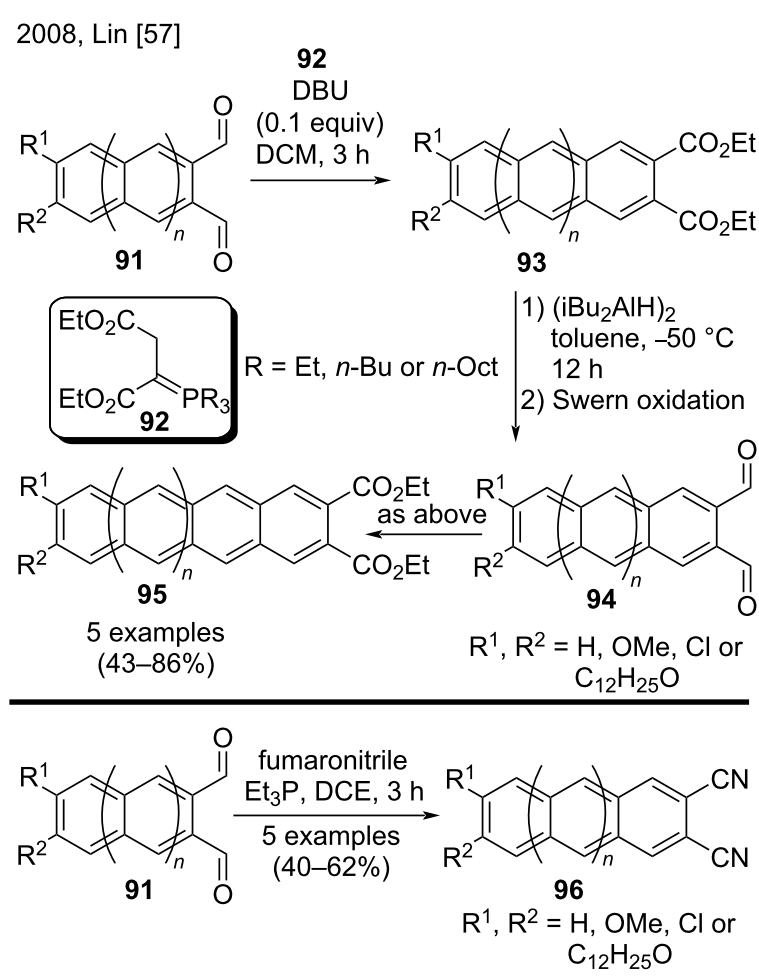

Scheme 23: Homo-elongation protocol for the synthesis of substituted acene diesters/dinitriles.

$\mathrm{BN}$ arenes include analogs in which a $\mathrm{C}=\mathrm{C}$ bond has been replaced with an isoelectronic BN bond. In 2014, Liu, Chrostowska, and co-workers synthesized two new parental BN anthracenes 100 and 105 (Scheme 24) [58]. The proposed method consisted of an adaptation of Dewar's original protocol to prepare 1,2-BN naphthalenes [58]. First, the authors submitted 3-amino-2-naphthoic acid (97) to a Sandmeyer reaction and obtained 98 . Then, a Curtius rearrangement of 98 by using diphenylphosphoryl azide (DPPA) yielded 3-iodonaphthalen-2-amine, that was subjected to a Suzuki cross-coupling with potassium vinyltrifluoroborate resulting in aminostyrene 99. The key step was borylative cyclization of precursor 99 and the subsequent treatment with $\mathrm{LiAlH}_{4}$ or MeLi, which resulted in $\mathrm{BN}$ anthracene 100a or 100b. On the other hand, the authors obtained BN anthracenes 105a and $\mathbf{1 0 5}$ by bxidation followed by Curtis rearrangement of the commercially available 1,4dibromo-2,5-dimethylbenzene (101), with subsequent Suzuki cross-coupling of compound $\mathbf{1 0 2}$ with potassium vinyltrifluoroborate, removal of the $N$-Boc protecting group of $\mathbf{1 0 3}$ with trifluoroacetic acid, and borylative cyclization of precursor aminostyrene 104 [58].

2014, Liu and Chrostowska [58]
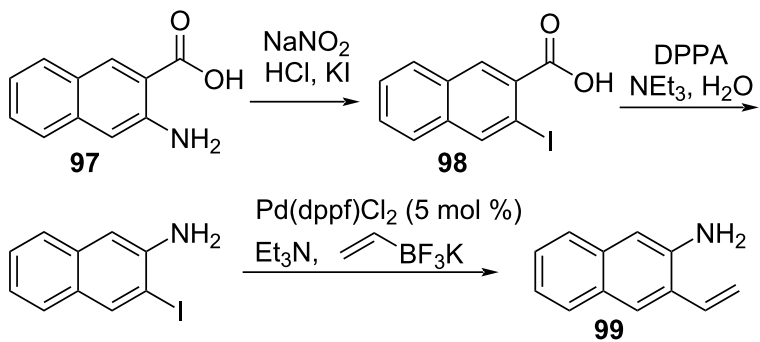

1) $\mathrm{BCl}_{3}$

2) $\mathrm{LiAlH}_{4}$ or MeLi
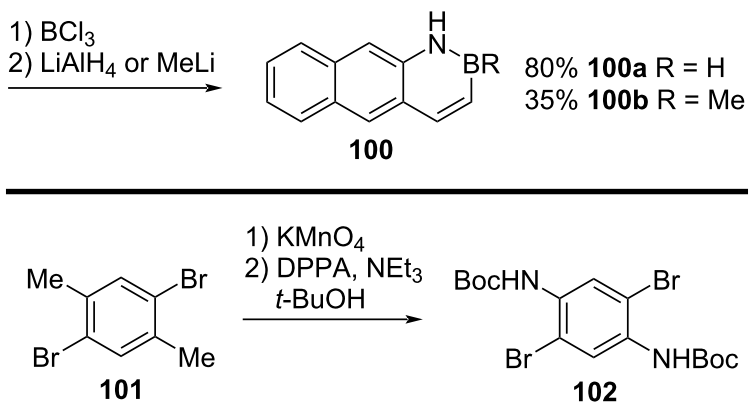

$\mathrm{Pd}(\mathrm{dppf}) \mathrm{Cl}_{2}(10 \mathrm{~mol} \%)$
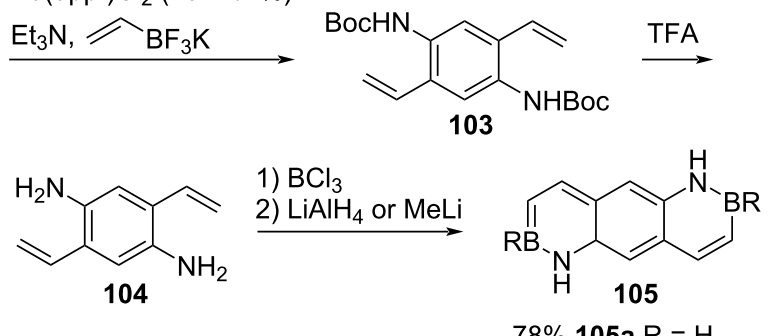

$78 \% 105 a \mathrm{R}=\mathrm{H}$

$48 \% 105 \mathrm{~b} R=\mathrm{Me}$

Scheme 24: Synthesis of two new parental BN anthracenes via borylative cyclization. 
Sparr's research group developed the 1,5-bifunctional organomagnesium alkoxide reagent $\mathbf{1 0 7}$, which converted esters into di- and monofunctionalized anthracenes (Scheme 25) [59]. They prepared this reagent by deprotonation-magnesiation of compound 106. Then, the treatment of aromatic esters with 107 produced dialkoxide 108, which could be easily converted to the substituted anthracenes $\mathbf{1 0 9}$ and $\mathbf{1 1 0}$ by varying the acidic workup procedures. In addition, they prepared 9-chloro-10phenylanthracene (112) in good yield (87\%) through diol 111 [59].

\section{7, Sparr [59]}<smiles>OC(c1ccccc1Br)c1ccccc1Br</smiles>

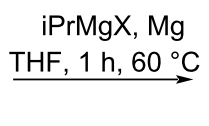<smiles>[M]C(OC)c1ccccc1C([M])c1ccccc1</smiles>
107

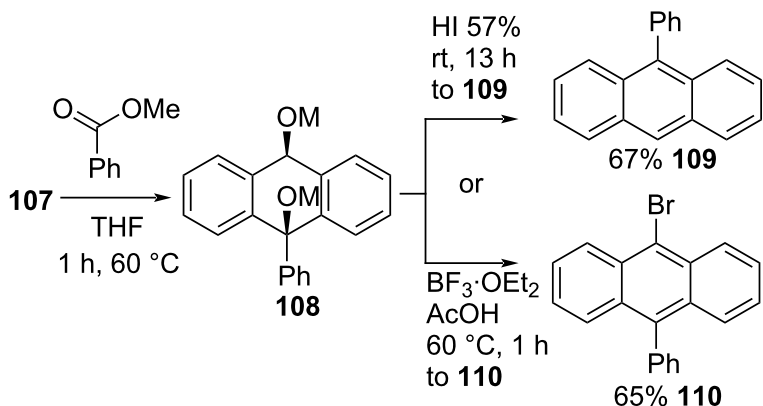

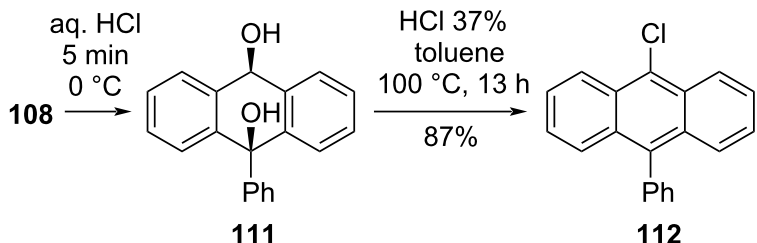

Scheme 25: Synthesis of substituted anthracenes from a bifunctional organomagnesium alkoxide.

\section{Synthesis of substituted benzo[a]anthracene and dibenzoanthracene derivatives Metal-catalyzed $\mathrm{C}-\mathrm{H}$ bond activation}

In 2009, Liang et al. reported an efficient and highly regioselective route to construct substituted tetracyclic benz $[a]$ anthracene derivatives 115 (Scheme 26) [60]. For this purpose, the authors developed an efficient palladium-catalyzed tandem $\mathrm{C}-\mathrm{H}$ activation/bis-cyclization reaction of propargylic carbonates 113 with terminal alkynes 114. The scope of this reaction consisted of 12 examples that were synthesized in moderate to good yields (40-87\%). The authors obtained the best yields by using electron-deficient aryl alkynes or secondary carbonates with electron-rich arene substituents $(\mathbf{1 1 5} \mathbf{a}-\mathbf{d})$. The authors also em- ployed aliphatic alkynes in this methodology, but they obtained lower yields [60].

2009, Liang [60]

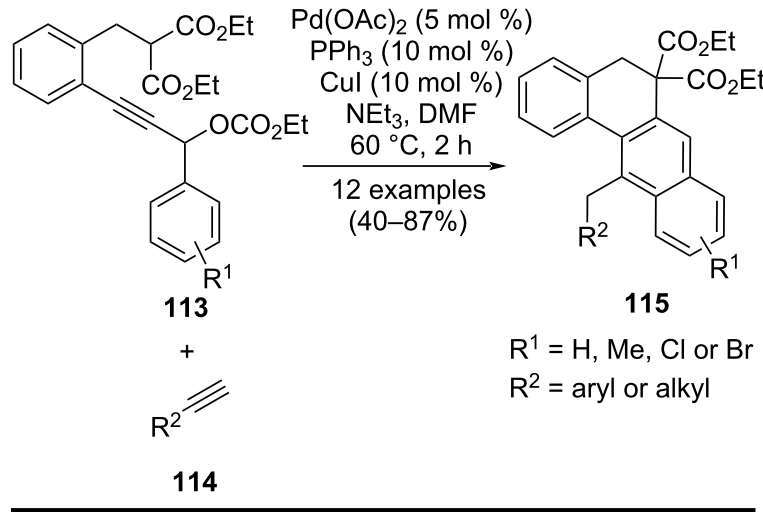

selected examples

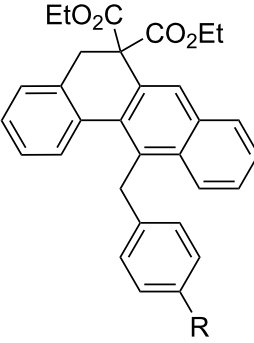

$87 \% 115 a \mathrm{R}=\mathrm{Cl}$ $83 \% 115 b \mathrm{R}=\mathrm{B}$

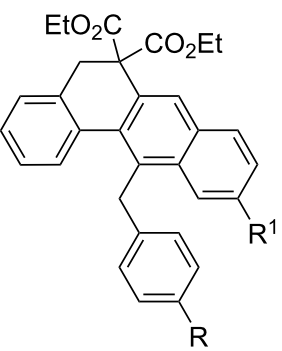

$86 \% 115 \mathrm{c} R=\mathrm{H}, \mathrm{R}^{1}=\mathrm{Me}$ $77 \% 115 d \mathrm{R}=\mathrm{OMe}, \mathrm{R}^{1}=\mathrm{H}$
Scheme 26: Palladium-catalyzed tandem C-H activation/bis-cyclization of propargylic carbonates.

In a study published in 2011, Kakiuchi and co-workers reported a new method to synthesize dibenzo $[a, h]$ anthracenes and picene derivatives by a ruthenium-catalyzed regioselective $\mathrm{C}-\mathrm{H}$ arylation of aromatic ketones (Scheme 27) [61]. The authors coupled acetophenone derivatives 116 and 1,4-benzenediboronates 117 at a 2:1 ratio, to obtain $p$-terphenyl derivatives 118. In the second step, the conversion of the acetyl group of compounds 118 to an ethynyl group afforded diethynylterphenyls 119. In the last step, a platinum-catalyzed intramolecular cycloaromatization of $\mathbf{1 1 9}$ provided dibenzo[ $a, h]$ anthracenes 120 bearing methyl and alkoxy groups in low to moderate yields $(26-51 \%)$ [61].

\section{Metal-catalyzed intramolecular double-cyclization}

In 2012, Nishiyama's research group synthesized dibenzo $[a, h]$ anthracenes by the Pd-catalyzed intramolecular double-cyclization of $p$-styrylstilbene derivatives for the first time (Scheme 28) [62]. The authors prepared dibenzo $[a, h]$ anthracene (122a (41 and $84 \%$ yield) and two de- 


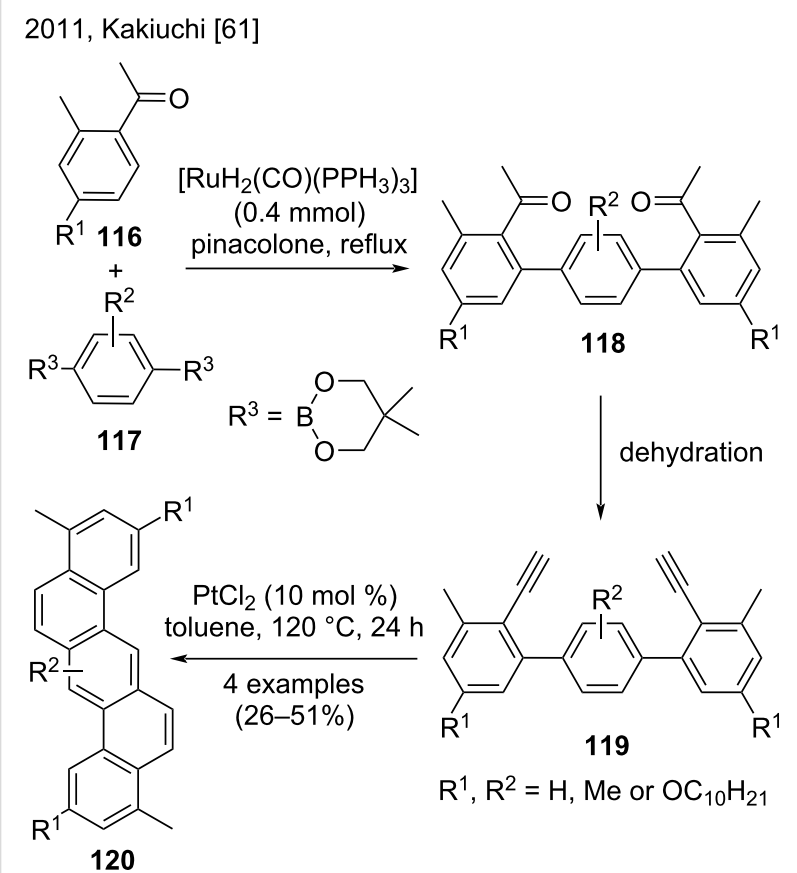

Scheme 27: Ruthenium-catalyzed C-H arylation of acetophenone derivatives with arenediboronates.

rivatives 122b ( $41 \%$ yield), and $\mathbf{1 2 4}$ ( $15 \%$ yield) via Pd-catalyzed intramolecular double-cyclization of the corresponding $(Z, Z)$-p-styrylstilbene derivatives $121 \mathbf{a}-\mathbf{c}$ and 123a, prepared according to the literature. However, when they carried out the reaction by using $(E, E)$-121a instead of $(Z, Z)$-121a under the same conditions, cyclization did not occur, so they did not detect the corresponding dibenzo[a,h]anthracene [62].

2012, Nishiyama [62]
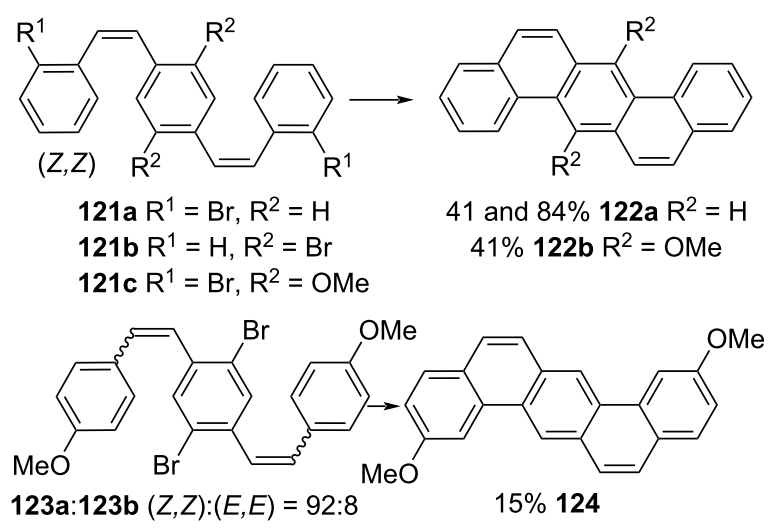

conditions: $\mathrm{Pd}(\mathrm{OAc})_{2}(0.01 \mathrm{mmol}), \mathrm{K}_{2} \mathrm{CO}_{3}(0.60 \mathrm{mmol})$ DMF, $110^{\circ} \mathrm{C}, 12 \mathrm{~h}$

Scheme 28: Pd-catalyzed intramolecular cyclization of $(Z, Z)-p$-styrylstilbene derivatives.
Sakaguchi, Nakae, and co-workers synthesized halogenated dibenzo $[a, h]$ anthracenes 126a-c and 5,8-diiodopicenes from dibromo- or diiodoethynylterphenyl compounds $\mathbf{1 2 5}$ via a AuCl-catalyzed intramolecular double cyclization (Scheme 29) [63]. The authors investigated the regioselectivity of the double cyclization and concluded that the reaction strongly depended on the position of the ethynyl groups in the terphenyl compounds. Terphenyls $\mathbf{1 2 5}$ were the most appropriate to prepare dibenzo[ $a, h]$ anthracenes in good yield (49-92\%). AuCl was a notable catalyst because it maintained high cyclization activity for iodoethynyl groups [63].

2012, Sakaguchi and Nakae [63]

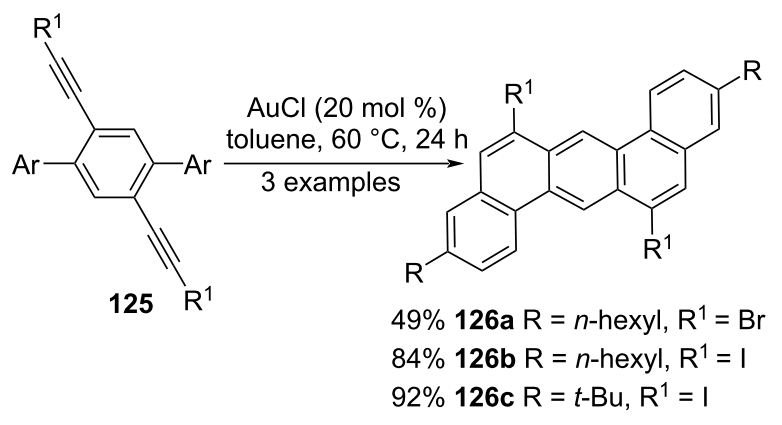

Scheme 29: AuCl-catalyzed double cyclization of diiodoethynylterphenyl compounds.

\section{Intramolecular cyclization}

In 2009, Swager's research group published the synthesis of fluorescent macrocycles based on 1,3-butadiyne-bridged dibenzo[ $a, j]$ anthracene subunits via a multistep route (Scheme 30) [64]. They synthesized substituted dibenzo[a,j]anthracenes 129a and 129b in two steps. First, they subjected dibromides 127 to a double Suzuki coupling with 4-alkylphenylboronic acids, to obtain the terphenyl derivatives 128. Then, the authors converted compounds $\mathbf{1 2 8}$, in moderate yield $(54-55 \%)$, to the corresponding 6,8-diiododibenzo $[a, j]$ anthracenes 129a and 129b via double iodonium-induced electrophilic cyclization. The terphenyl 130 was converted to the diiododibenzo $[a, j]$ anthracene derivative $\mathbf{1 3 2}$ in two steps comprising cyclization and further treatment of intermediate $\mathbf{1 3 1}$ with sulfuric acid [64].

Watanabe and co-workers investigated the oxidative photocyclization of 1,3-distyrylbenzene derivatives $\mathbf{1 3 3}$ bearing different substituents at position 2 in order to find efficient blocking groups to afford dibenzoanthracene derivatives (Scheme 31) [65]. For the first time, their results established that butylthio and diphenylphosphino groups performed well as blocking groups, to give the corresponding substituted dibenzo[ $a, j]$ anthracenes $\mathbf{1 3 4 a}$ and $\mathbf{1 3 4 b}$, respectively. The 

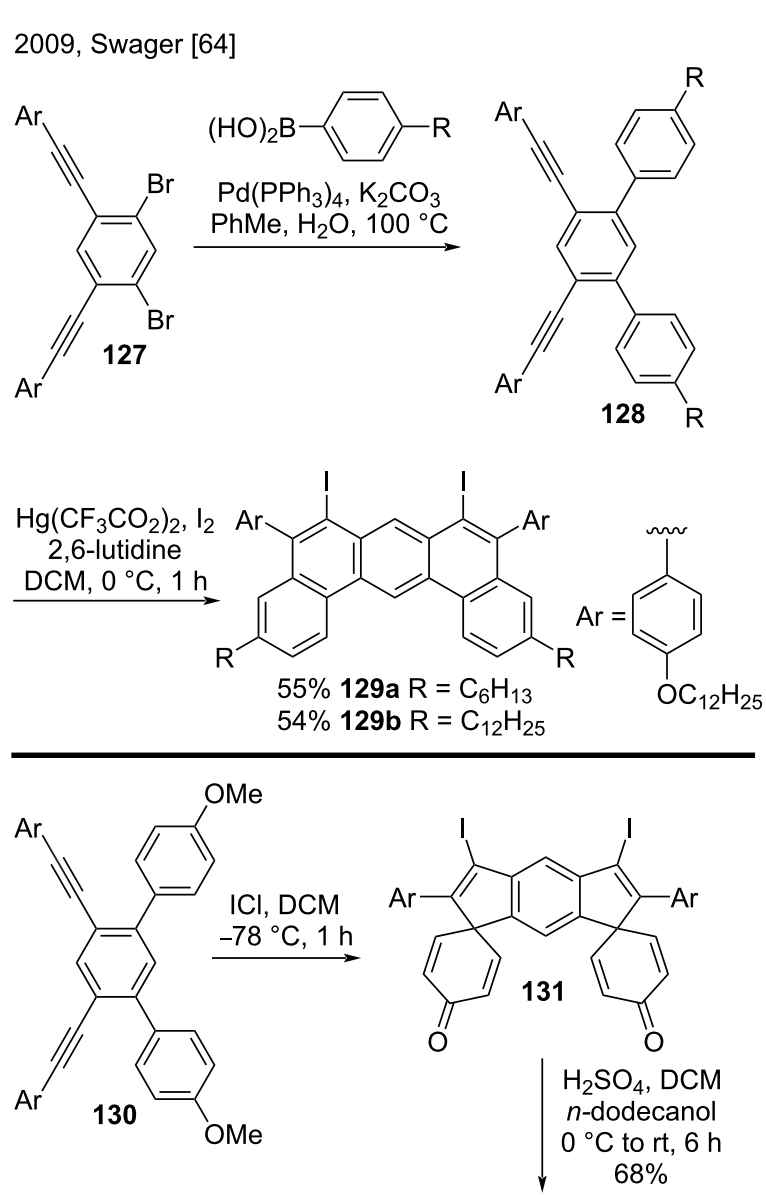<smiles>CCOc1ccc(C)cc1[Al]</smiles><smiles>CCCCCOc1ccc2c(c1)c(Br)c(I)c1cc3c(I)c(Br)c4cc(OCCCCCCCCCO)ccc4c3cc12</smiles>

Scheme 30: lodonium-induced electrophilic cyclization of terphenyl derivatives.

authors also used 1,3-distyrylbenzene $\mathbf{1 3 3}$ substituted with chloro and dodecylthio groups and obtained the dibenzo[ $a, j]$ anthracenes $\mathbf{1 3 4 c}$ and 134d in moderate yields (53-62\%). However, when they employed 1,3-distyrylbenzenes substituted with methyl, trimethylsilyl, dimethylamino, butoxy, or fluoro groups, they only obtained compounds similar to benzo[c]chrysene derivative 135 [65].

In 2015, Maly and co-workers reported a two-step synthetic route to obtain substituted 2,3,5,6-tetraalkoxydibenzo[ $a, c]$ anthracenes $\mathbf{1 3 9}$ bearing $\mathrm{H}, \mathrm{CN}$, or OMe groups at positions 11 and 12, to study their liquid crystalline properties (Scheme 32) [66]. Their methodology started with a Suzuki coupling reaction of substituted dibromonaphthalenes $\mathbf{1 3 6}$ and boronate diesters $\mathbf{1 3 7}$, to provide the corresponding 2,3-

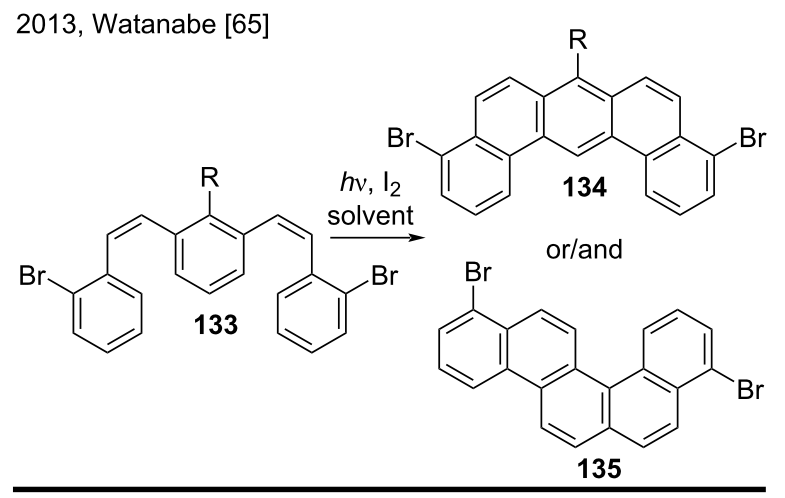

substrate scope<smiles>[R]c1c2ccc3c(Br)cccc3c2cc2c1ccc1c(Br)cccc12</smiles>

$63 \% 134 \mathrm{a} R=\mathrm{SBu}$

$25 \% 134 b \mathrm{R}=\mathrm{PPh} 2$

$62 \% 134 \mathrm{c} R=\mathrm{Cl}$

$53 \% 134 d \mathrm{R}=\mathrm{SC}_{12} \mathrm{H}_{25}$

Scheme 31: Oxidative photocyclization of 1,3-distyrylbenzene derivatives.

diphenylnaphthalenes 138. Then, an oxidative cyclization of 138 in the presence of $\mathrm{FeCl}_{3}$ afforded dibenzo[a,c]anthracenes 139a and 139b in moderate yields (58-68\%). On the other hand, they obtained dibenzo[a,c]anthracenes $139 \mathbf{c}-\mathbf{e}$ in low to moderate yields (15-54\%) when they used DDQ/MeSO ${ }_{3} \mathrm{H}$ instead of $\mathrm{FeCl}_{3}[66]$.

\section{5, Maly [66]}
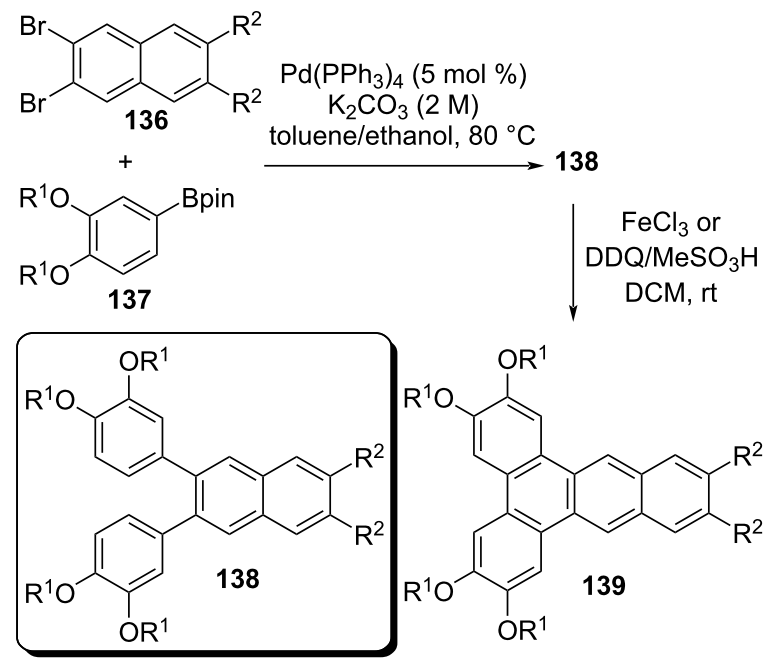

$58 \% 139 a \mathrm{R}^{1}=\mathrm{C}_{10} \mathrm{H}_{21}, \mathrm{R}^{2}=\mathrm{OMe}$ $68 \% 139 b R^{1}=\mathrm{C}_{10} \mathrm{H}_{21}, \mathrm{R}^{2}=\mathrm{H}$ $54 \% 139 c \mathrm{R}^{1}=\mathrm{C}_{8} \mathrm{H}_{16}, \mathrm{R}^{2}=\mathrm{CN}$ $35 \% 139 d R^{1}=\mathrm{C}_{10} \mathrm{H}_{21}, \mathrm{R}^{2}=\mathrm{CN}$ $15 \% 139 e R^{1}=\mathrm{C}_{12} \mathrm{H}_{25}, \mathrm{R}^{2}=\mathrm{CN}$

Scheme 32: Oxidative cyclization of 2,3-diphenylnaphthalenes. 
In a study published in 2018 , de Koning and co-workers reported a new methodology to synthesize the benzo[ $a]$ anthracene skeleton of angucycline derivatives 146 by using a multistep strategy based on Suzuki-Miyaura, isomerization, and ringclosing metathesis reactions (Scheme 33) [67]. The commercially available 2-bromonaphthoquinone (140) reacted with vinylacetic acid to afford the allylated compound 141. Then, reduction of $\mathbf{1 4 1}$ and sequential $O$-methyl-protection furnished naphthalene 142. A Suzuki-Miyaura coupling reaction between 142 and boronic acids afforded 2-naphthylbenzaldehydes 143, which were further subjected to a Wittig reaction affording naphthalenes 144. Isomerization of compounds 144 produced substituted styrenes $\mathbf{1 4 5}$. With the styrenes 145 in hands, the authors employed the Grubbs II catalyst-promoted ring closure to obtain the benzo $[a]$ anthracenes $146 \mathrm{a}$ (85\% yield) and $\mathbf{1 4 6 b}$ (43\% yield) [67].

2018, de Koning [67]
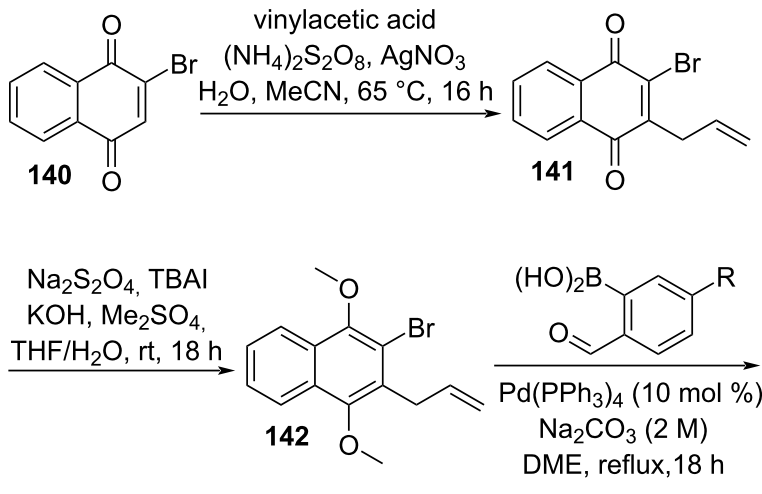

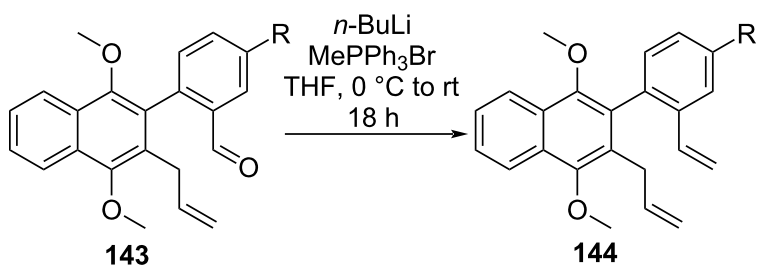<smiles>[R]c1ccc(-c2c(/C=C/C)c(OC)c3ccccc3c2OC)c(C=C)c1</smiles>

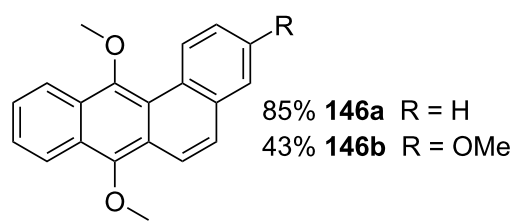

Scheme 33: Suzuki-Miyaura/isomerization/ring closing metathesis strategy to synthesize benz[a]anthracenes.

\section{Other procedures}

In 2012, Singh and co-workers performed green syntheses of oxa-aza-benzo $[a]$ anthracene and oxa-aza-phenanthrene derivatives 151 and 152 via a sequential one-pot reaction in an aqueous micellar system (Scheme 34) [68]. This methodology comprised reactions of isoquinoline (147), phenacyl bromides 148 bearing $\mathrm{OMe}, \mathrm{NO}_{2}$, or $\mathrm{Cl}$ groups, and epoxides (149 and 150), DBU as catalyst, CTAB as surfactant, and water as solvent. The use of cyclohexene oxide (149) provided oxa-azabenzo[ $a]$ anthracene derivatives $\mathbf{1 5 1}$ in excellent yields (90-96\%). On the other hand, the use of styrene oxide (150) provided oxa-aza-phenanthrene derivatives $\mathbf{1 5 2}$, also in excellent yields (91-98\%) [68].

2012, Singh [68]<smiles>CC12CCCCC1O2</smiles>

or<smiles>c1ccc2cnccc2c1</smiles><smiles>c1ccc([AsH2+]2CO2)cc1</smiles>
$\mathrm{CTAB}$, water DBU $(20 \mathrm{~mol} \%)$ 147 rt, $15-50 \mathrm{~min}$<smiles>O=C(c1ccc(F)cc1)C1C2CCCCC2OC2c3ccccc3C=CN21</smiles>

4 examples $90-96 \%$<smiles>[R]c1ccc(C(=O)CBr)cc1</smiles>

$\mathrm{R}=\mathrm{H}, \mathrm{OMe}, \mathrm{NO}_{2}$ or $\mathrm{Cl}$<smiles>[R]c1ccc(C(=O)[C@@H]2C[C@H](c3ccccc3)O[C@H]3c4ccccc4C=CN23)cc1</smiles>

Scheme 34: Green synthesis of oxa-aza-benzo[a]anthracene and oxaaza-phenanthrene derivatives.

In 2015, Gribble et al. published a new method to synthesize dibenzo[ $a, c]$ anthracene (158) based on a triple benzannulation of naphthalene derivative $\mathbf{1 5 3}$ via a 1,3,6-naphthotriyne synthetic equivalent 155 (Scheme 35) [69]. First, reaction of brominated naphthalene 153 with PhLi yielded compound 154, which collapsed to naphthotriyne $\mathbf{1 5 5}$ at elevated temperatures. Sequential addition of furan generated the trisadduct 156. Then, dibenz $[a, c]$ anthracene 158 was obtained in good yield (86\%) in two steps by hydrogenation of $\mathbf{1 5 6}$ and further dehydration of 157 under reflux with concentrated $\mathrm{HCl}$ [69].

\section{Synthesis of anthraquinone derivatives Friedel-Crafts intramolecular cyclization}

In 2013, Hilt and co-workers synthesized symmetric and asymmetric anthraquinone derivatives 162 bearing $\mathrm{Br}, \mathrm{Me}$, or $\mathrm{OMe}$ groups via $\mathrm{ZnI}_{2}$-catalyzed Diels-Alder reactions/DDQ oxida- 


\section{5, Gribble [69]}

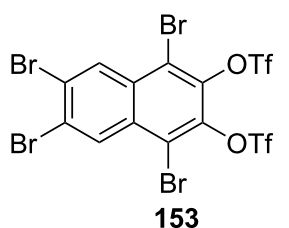

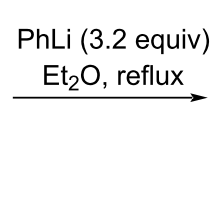

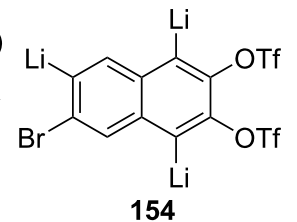<smiles></smiles><smiles>Cc1cocc1C</smiles>

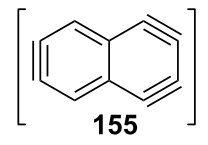

$\mathrm{Pd} / \mathrm{C} 10 \mathrm{~mol} \%, \mathrm{H}_{2}$ $\mathrm{MeOH}, \mathrm{DCM}, 24 \mathrm{~h}$

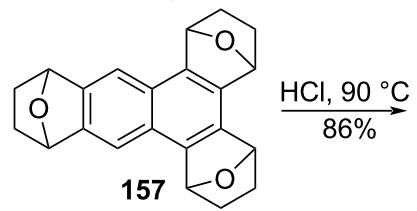<smiles></smiles>

Scheme 35: Triple benzannulation of substituted naphtalene via a 1,3,6-naphthotriyne synthetic equivalent.

tion of 1,3-dienes $\mathbf{1 5 9}$ and aroyl-substituted propiolates $\mathbf{1 6 0}$ (Scheme 36) [70]. Subsequently, the authors performed an intramolecular Friedel-Crafts cyclization of the corresponding derivatives 161 by using concentrated sulfuric acid. The authors noted that the more electron-donating alkyl or methoxy groups were present in the aromatic ring, the more efficient the Friedel-Crafts-type cyclization would be. Representative examples included substituted anthraquinones 162a and 162b, that were obtained in very good yields (92-96\%) [70].

In 2014, Serevicius and co-workers synthesized two derivatives of substituted anthraquinones $\mathbf{1 6 6}$ aiming at further preparation of 9,10-diphenyltanthracenes 167 (Scheme 37) [71]. First, they reacted arenes 163 with phthalic anhydride (164) in the presence of aluminum chloride and hydrochloric acid, to obtain benzoylbenzoic acid derivatives 165 . Then, the $\mathrm{H}_{3} \mathrm{PO}_{4}$ promoted intramolecular cyclization of $\mathbf{1 6 5}$ led to anthraquinones 166a and 166b, which reacted with arylmagnesium bromides to afford the substituted 9,10-diphenylanthracenes 167 in low yields (13-35\%). Despite that, this strategy was particularly interesting for the synthesis of anthraquinone derivatives by using different arenes [71].

Recently, Satyanarayana and Suchand developed a one-pot strategy to synthesize substituted anthraquinones 170 via palladium-catalyzed intermolecular direct acylation of aromatic aldehydes 169 and $o$-iodoesters 168 (Scheme 38) [72]. The overall
2013, Hilt [70]

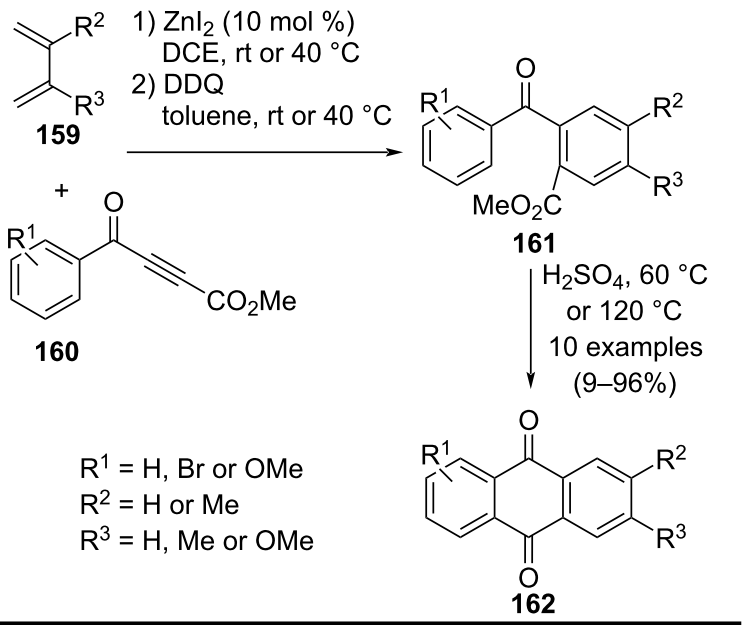

selected examples<smiles>COc1cc2c(cc1OC)C(=O)c1cc(C)c(C)cc1C2=O</smiles>

$96 \% 162 a$<smiles>COc1cc2c(c(OC)c1OC)C(=O)c1ccccc1C2=O</smiles>

$92 \% 162 b$
Scheme 36: Zinc iodide-catalyzed Diels-Alder reactions with 1,3dienes and aroyl propiolates followed by intramolecular Friedel-Crafts cyclization.

2014, Serevicius [71]

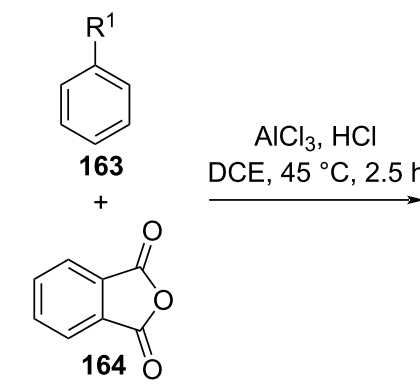<smiles>[R]c1ccc(C(=O)c2ccccc2C(=O)O)cc1</smiles>

165

$\mathrm{H}_{3} \mathrm{PO}_{4}$<smiles>[R]c1ccc(-c2c3ccccc3c(-c3ccc([R])cc3)c3cc(F)ccc23)cc1</smiles>
$160^{\circ} \mathrm{C}, 4.5 \mathrm{~h}$

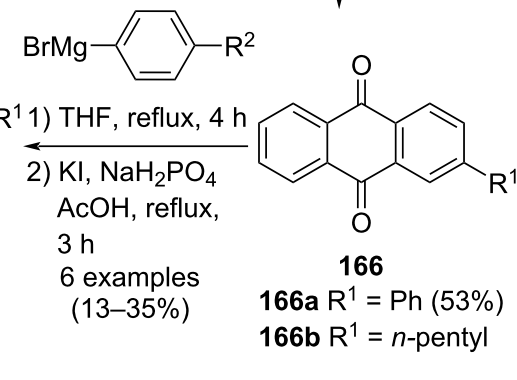

167

$\mathrm{R}^{2}=\mathrm{H}, \mathrm{Me}$ or $n$-hexyl

Scheme 37: $\mathrm{H}_{3} \mathrm{PO}_{4}$-promoted intramolecular cyclization of substituted benzoic acids. 
process involved sequential Pd-catalyzed intermolecular acylation $/ \mathrm{H}_{2} \mathrm{SO}_{4}$-promoted intramolecular Friedel-Crafts cyclization. The authors prepared substituted anthraquinones bearing $\mathrm{Me}, \mathrm{OMe}, \mathrm{OH}, \mathrm{Br}, \mathrm{F}$, or other groups, such as anthraquinones 170a-g, in moderate to good yields (55-69\%). The reaction proved efficient mainly with electron-donating substituents on the benzaldeydes 169 [72].

2019, Satyanarayana and Suchand [72]

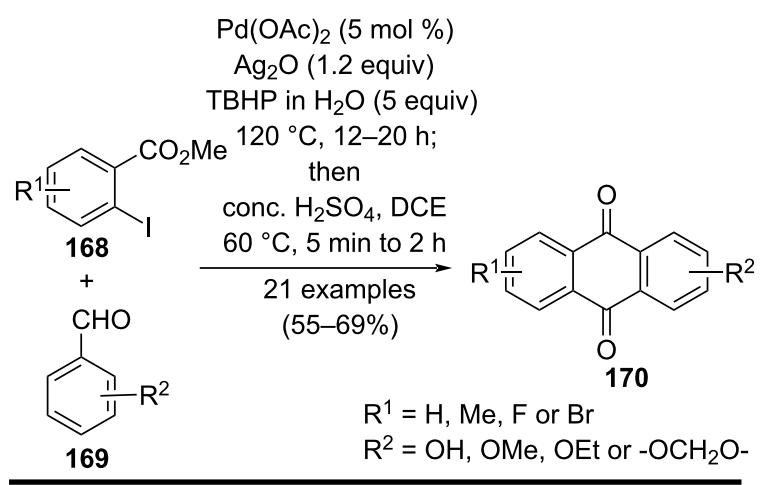

selected examples<smiles>[R]c1cc2c(cc1[R])C(=O)c1ccccc1C2=O</smiles><smiles>[R]c1ccc2c(c1)C(=O)c1ccc([R])cc1C2=O</smiles>

$69 \% 170 a R^{1}=H, R^{2}=O H$

$64 \% 170$ e $R^{1}=M e, R^{2}=O M e$ $62 \% 170 b R^{1}=H, R^{2}=$ OMe $\quad 63 \% 170 f R^{1}=F, R^{2}=O M e$ $68 \% 170 \mathrm{c} \mathrm{R}^{1}=\mathrm{OMe}, \mathrm{R}^{2}=\mathrm{OMe} 62 \% 170 \mathrm{~g} \mathrm{R}^{1}=\mathrm{Br}, \mathrm{R}^{2}=\mathrm{OMe}$ $55 \% 170 \mathrm{~d} \mathrm{R}^{1}=\mathrm{OMe}, \mathrm{R}^{2}=\mathrm{OH}$

Scheme 38: Palladium-catalyzed intermolecular direct acylation of aromatic aldehydes and $o$-iodoesters.

\section{Cycloaddition reactions}

In 2014, Gao, Li, and their co-workers published a facile strategy to synthesize polysubstituted aromatic compounds from the reaction of quinones or maleimides with $\beta$-enamino esters (Scheme 39) [73]. They synthesized anthraquinone derivatives $\mathbf{1 7 3}$ in good yield (62-94\%) via a cycloaddition/oxidative aromatization sequence involving quinone $\mathbf{1 7 1}$ and substituted $\beta$-enamino esters 172 as precursors. They prepared anthraquinone 173a starting from three different $\beta$-enamino esters; a less bulky $\beta$-enamino ester favored the reaction. The scope of the reaction also included anthraquinones $\mathbf{1 7 3 b}$ and 173c, obtained in good yields (74-94\%) [73].

In 2015, in a related approach, Lee et al. disclosed a direct onepot synthesis of anthraquinones and tetracenediones by using L-proline as organocatalyst and benzoic acid as additive (Scheme 40) [74]. They synthesized substituted anthraquinones
2014, Gao and Li [73]

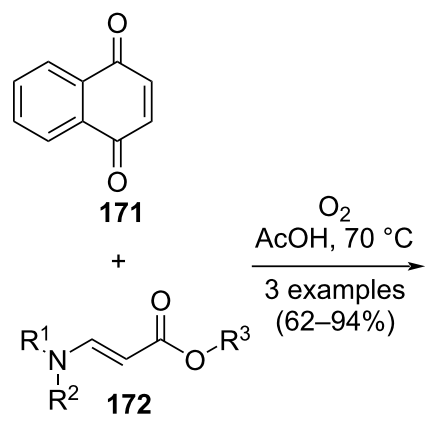<smiles>[R]OC(=O)c1cc(C(=O)O[R])c2c(c1)C(=O)c1ccccc1C2=O</smiles>

$62-85 \% 173 a R^{3}=E t$

$94 \% 173 b \mathrm{R}^{3}=\mathrm{Me}$

$74 \% 173 c R^{3}=i B u$

Scheme 39: Cycloaddition/oxidative aromatization of quinone and $\beta$-enamino esters.

bearing Me, Et, or hydroxy groups, such as compounds $\mathbf{1 7 6 a - e}$, in moderate to good yields $(45-94 \%)$ through a $[4+2]$ cycloaddition reaction of 1,4-substituted naphthoquinones 174 and $\alpha, \beta$ unsaturated aldehydes 175 catalyzed by L-proline. During optimization studies, the authors observed that benzoic acid played an important role in the formation of quinone compounds, increasing the yields and decreasing reaction times [74].

2015, Lee [74]

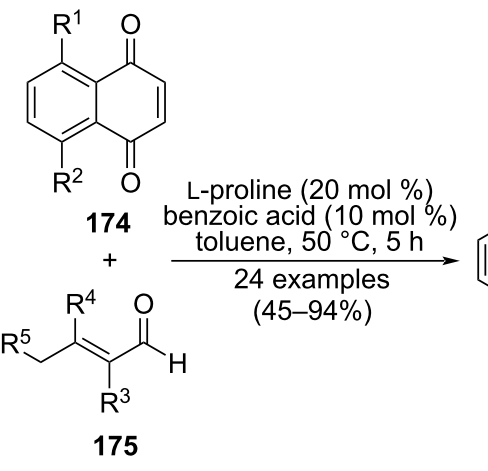<smiles>[R]c1cc2c(c([R])c1[R])C(=O)c1c([R])ccc([R])c1C2=O</smiles>
176

175

selected examples<smiles>[R6]c1cccc2c1C(=O)c1c(O)ccc(O)c1C2=O</smiles><smiles>[R1]c1cccc2c1C(=O)c1ccccc1C2=O</smiles><smiles>COc1ccc(OC)c2c1C(=O)c1ccc(C)cc1C2=O</smiles>

$93 \% 176 a R^{5}=$ Et $\quad 83 \% 176 c R^{1}=O M e \quad 93 \% 176 e$ $90 \% 176 b R^{5}=\mathrm{Me} 80 \% 176 d R^{1}=\mathrm{OH}$

Scheme 40: L-Proline-catalyzed [4 + 2] cycloaddition reaction of naphthoquinones and $\alpha, \beta$-unsaturated aldehydes. 
Recently, Takeuchi's research group synthesized polysubstituted anthraquinones $\mathbf{1 7 9}$ in moderate to good yields (42-93\%) via an iridium-catalyzed $[2+2+2]$ cycloaddition of $1,2-$ bis(propiolyl)benzene derivative $\mathbf{1 7 8}$ and terminal/internal alkynes 177 (Scheme 41) [75]. The authors performed the reactions with terminal alkynes in toluene, and reactions with internal alkynes in dichloromethane (DCM). They noted that the use of 1,2-bis(diphenylphosphino)ethane (DPPE) as ligand improved the yield of the anthraquinones. Representative examples included anthraquinones 179a and 179b obtained from terminal alkynes and 179c and 179d from internal alkynes [75].

\section{9, Takeuchi [75]}

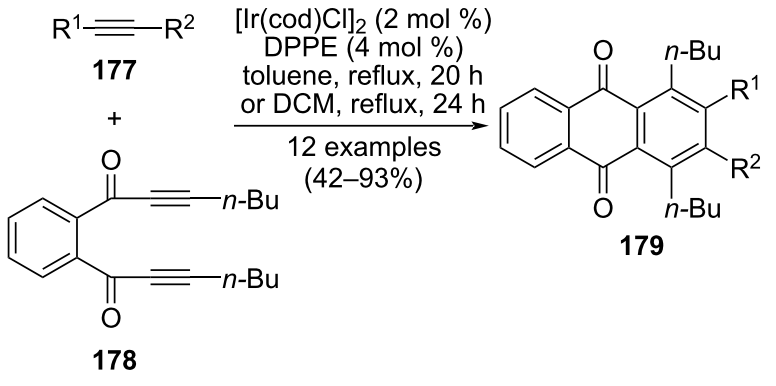

selected examples<smiles>[R]c1c([R])c([R])c2c(c1[R19])C(=O)c1ccccc1C2=O</smiles><smiles>[R]c1c([R])c([R])c2c(c1[R19])C(=O)c1ccccc1C2=O</smiles>

$93 \% 179 a \mathrm{R}^{1}=n$-Oct, $\mathrm{R}^{2}=\mathrm{H} \quad 86 \% 179 \mathrm{c} \mathrm{R} \mathrm{R}^{1}, \mathrm{R}^{2}=\mathrm{CH}_{2} \mathrm{OH}$ $92 \% 179 b \mathrm{R}^{1}=n-\mathrm{Hex}, \mathrm{R}^{2}=\mathrm{H} \quad 82 \% 179 \mathrm{~d} \mathrm{R} \mathrm{R}^{1}, \mathrm{R}^{2}=\mathrm{CH}_{2} \mathrm{OMe}$

Scheme 41: Iridium-catalyzed [2+2+2] cycloaddition of a 1,2 bis(propiolyl)benzene derivative with alkynes.

\section{Multicomponent reactions}

In 2009, Singh and co-workers reported a solvent-free methodology to synthesize tetrahydrobenzo[ $[a]$ xanthene-11-ones $\mathbf{1 8 4}$ and diazabenzo[ $a]$ anthracene-9,11-dione derivatives $\mathbf{1 8 5}$ in good yields via a multicomponent reaction (Scheme 42) [76] This methodology was based on the cyclocondensation of aromatic aldehydes 180, $\beta$-naphthol (181), and cyclic 1,3-dicarbonyl compounds 182 or 183 , catalyzed by $\mathrm{InCl}_{3}$ or $\mathrm{P}_{2} \mathrm{O}_{5}$. The authors achieved the best results (63-88\% yield) when they carried out the reactions with $\mathrm{InCl}_{3}$ instead of $\mathrm{P}_{2} \mathrm{O}_{5}$. However, the reactions with some aliphatic aldehydes such as cinnamaldehyde, isobutyraldehyde, and cyclohexanecarboxaldehyde did not generate the expected products [76]. Sun and co-workers modified the method proposed by Singh. In 2011, they reported a method that employed molecular iodine as the catalyst, under microwave radiation as heat source, and obtained tetrahydrobenzo $[a]$ xanthene-11-one and diazabenzo $[a]$ anthracene- 9,11-dione derivatives in good to excellent yields (70-94\%) [77]. Then, in 2012, Sun and co-workers reported another method employing molecular iodine as catalyst under reflux with acetic acid instead of microwave radiation and also obtained good yields (66-89\%) [78]. Because the three methodologies provided good yields, the authors were able to synthesize substituted derivatives, such as compounds 184 and 185 , bearing diverse aryl groups, derived from aromatic aldehydes. However, the direct comparison among the yields of diazabenzo[ $a]$ anthracene-9,11-diones $\mathbf{1 8 5 a - d}$ shows that the methodology developed in 2011 by Sun and co-workers [77] provided better results.

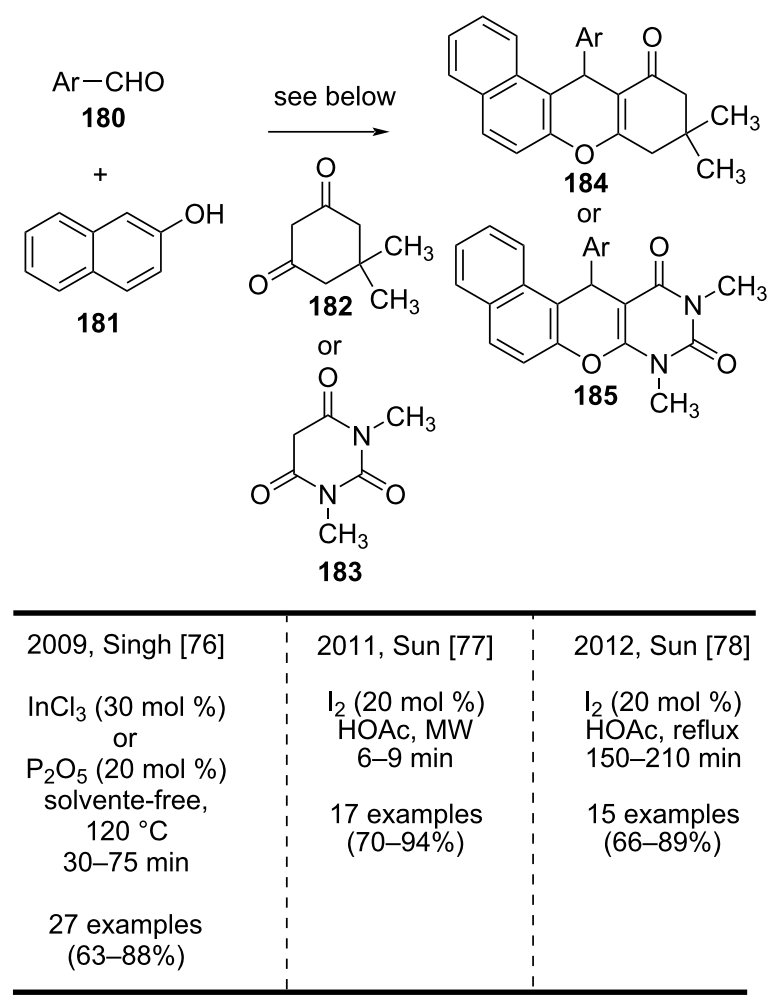

selected examples (Singh/Sun 2011/Sun 2012) [76-78]

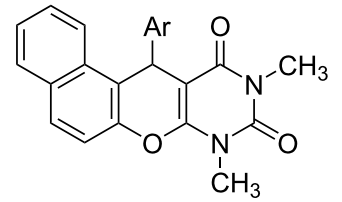

$68 \% / 75 \% / 70 \% 185 \mathrm{a} \mathrm{Ar}=\mathrm{Ph}$

$65 \% / 72 \% / 68 \% 185 \mathrm{~b} \mathrm{Ar}=p-\mathrm{NO}_{2} \mathrm{C}_{6} \mathrm{H}_{4}$

$67 \% / 74 \% / 70 \% 185 \mathrm{c} \mathrm{Ar}=0-\mathrm{ClC}_{6} \mathrm{H}_{4}$

$70 \% / 78 \% / 74 \% 185 \mathrm{~d} \mathrm{Ar}=p-\mathrm{MeC}_{6} \mathrm{H}_{4}$

Scheme 42: Synthesis of several anthraquinone derivatives by using $\mathrm{InCl}_{3}$ and molecular iodine.

In a related approach, Estévez-Braun and co-workers synthesized dibenzo[ $a, h]$ anthracene-12,13-diones $\mathbf{1 8 8}$ from 
2-hydroxy-1,4-naphthoquinone (186), $\beta$-naphthol (181), and aromatic aldehydes $\mathbf{1 8 7}$ through a multicomponent reaction that used $\mathrm{InCl}_{3}$ as catalyst under solvent-free conditions (Scheme 43) [79]. The authors used various heteroaromatic aldehydes and substituted aromatic aldehydes containing electron-donating and electron-withdrawing substituents, to obtain the ortho adducts 188 in variable yields (14-74\%). The use of pyridine-3-carbaldehyde and 2,4,5-trimethoxybenzaldehyde also afforded the corresponding para-adducts $\mathbf{1 8 9}$ in different proportions in the reaction mixture. As expected, when the authors used aliphatic aldehydes, they did not detect the corresponding derivatives 188 [79].

\section{4, Estévez-Braun [79]}

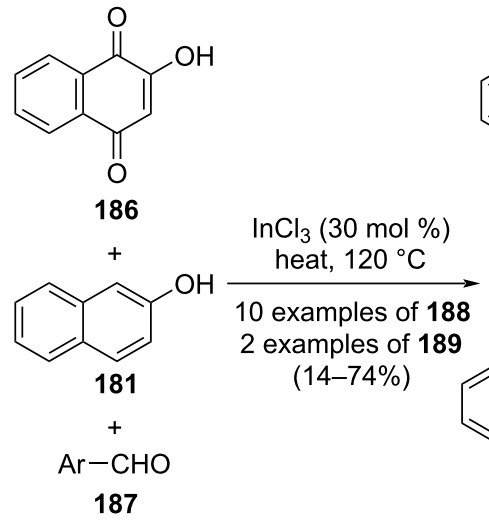<smiles>O=C1C(=O)c2ccccc2C2=C1C(Br)c1c(ccc3ccccc13)OC1=C(C(=O)c3ccccc3C1=O)C2[Al]</smiles>

189

Scheme 43: Indium-catalyzed multicomponent reactions employing 2-hydroxy-1,4-naphthoquinone (186), $\beta$-naphthol (181), and aromatic aldehydes.

\section{Other procedures}

In 2009, Naeimi and Namdari published a one-pot synthesis of substituted anthraquinone derivatives 191 from phthalic anhydride (164) and several arenes 190 by using a combined system of $\mathrm{AlCl}_{3}$ and $\mathrm{MeSO}_{3} \mathrm{H}$ (Scheme 44) [80]. Arenes 190 containing electron-donating groups yielded the anthraquinone derivatives 191a-c in very good yields (80-93\%). On the other hand, reactions involving arenes $\mathbf{1 9 0}$ bearing electron-withdrawing substituents afforded the anthraquinone derivatives 191d-f in significantly lower yields (6-26\%) [80].

In 2017, Hong and co-workers reported another efficient protocol for the direct synthesis of substituted anthraquinones (Scheme 45) [81]. The authors employed palladium(II) acetate and visible light under $\mathrm{O}_{2}$ in the reactions between ethyl acrylate (192) and substituted diaryl carboxylic acids 193, to produce anthraquinones $\mathbf{1 9 4}$ in low to moderate yields (30-68\%). In a direct comparison with the methodology proposed by Hong for the synthesis of anthracenes, previously
2009, Naeimi and Namdari [80]

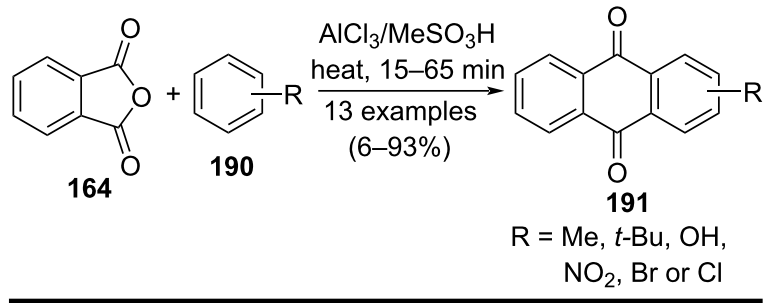

selected examples

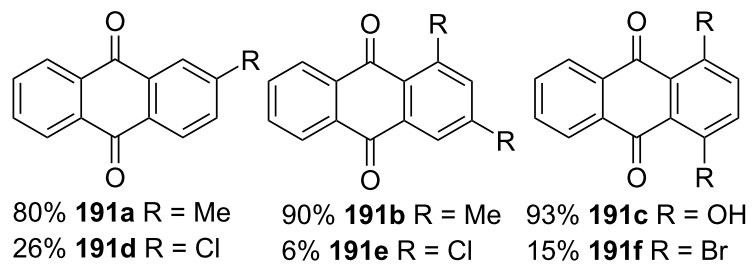

Scheme 44: Synthesis of substituted anthraquinones catalyzed by an $\mathrm{AlCl}_{3} / \mathrm{MeSO}_{3} \mathrm{H}$ system

shown in Scheme 7 [41], the key to obtaining anthraquinones was the photooxidation induced by visible light, which afforded the substituted anthraquinones 194. In this case, the effect of the aromatic ring substituents also affected the yield of the anthraquinones, as can be seen from the representative examples 194a-d [81].

\section{7, Hong [81]}

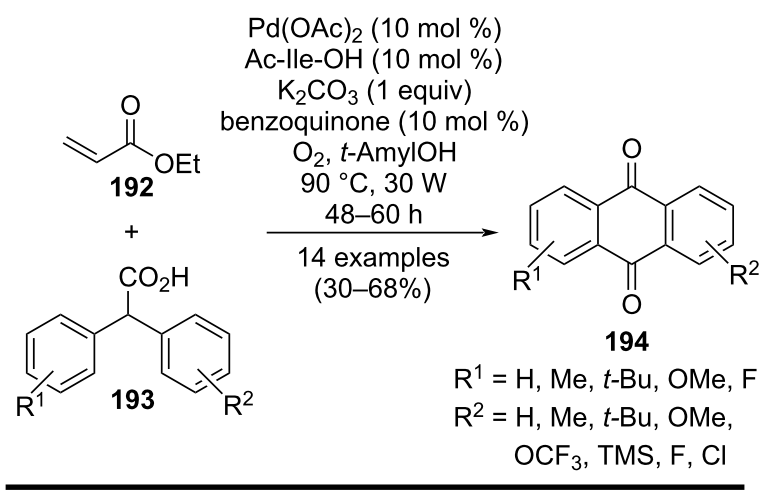

selected examples<smiles>O=C1c2ccccc2C(=O)c2ccccc21</smiles><smiles>Cc1ccc2c(c1)C(=O)c1ccccc1C2=O</smiles><smiles>[R]c1ccc2c(c1)C(=O)c1ccccc1C2=O</smiles>

$56 \% 194 a$ $54 \% 194 b$

$36 \% 194 \mathrm{c} R=\mathrm{C}$ $30 \% 194 d R=F$

Scheme 45: Palladium(II)-catalyzed/visible light-mediated synthesis of anthraquinones. 
In 2017, Mal and Basak applied a [4 + 2] anionic annulation of substituted cyanophthalides 195 with dienoates 196 and obtained 3-allylnaphthoates 197 (Scheme 46) [82]. Then, they converted the naphthoate derivatives $\mathbf{1 9 7}$ to the corresponding alcohols 198 by DIBAL-H reduction, and later to aldehydes 199 by Dess-Martin periodinane (DMP) oxidation. The aldehydes 199 were treated with BINOL- $\mathrm{PO}_{2} \mathrm{H}$ in chloroform, in the presence of air and light, to produce the corresponding anthraquinones 200 in excellent yields (93-99\%) [82].

2017, Mal and Basak [82]<smiles>[X]c1ccc2c(c1)C(C#N)OC2=O</smiles>

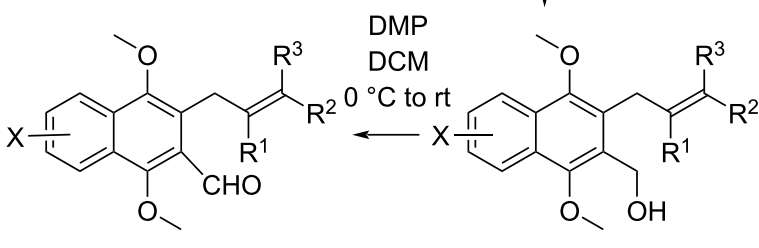
199 198<smiles>[R]c1cc2c(cc1[X])C(=O)c1cc([R])c([R])cc1C2=O</smiles>
200

Scheme 46: [4 +2] Anionic annulation reaction for the synthesis of substituted anthraquinones.

In this review, a more detailed discussion of different types of anthracene derivatives (e.g., anthracenophanes) that have been the subject of research interest for some time [1] cannot be included. Nevertheless, readers interested in this area should refer to several interesting articles on this subject such as the work of the research groups of Bettinger [83,84], Ohmori [85], and Novak [86].

\section{Conclusion}

In this review, we have highlighted the most recent preparative methods for anthracene derivatives. Among the many synthetic strategies reported in the last twelve years, metal-catalyzed/ promoted reactions, especially those with internal alkynes, have been the most used, possibly because they provide a simple and straightforward ring extension method to construct polycyclic aromatic compounds, especially anthracenes with substituents in the 2-, 3-, 6-, and 7-positions. Also, considering the difficulties and limitations of direct syntheses of anthracene derivatives, the considerable number of methodologies reported in recent years is truly surprising. Due to the wide applicability of anthracene and anthraquinone derivatives in important fields of science, the development of new synthetic methods is likely to increase. We hope that this review can serve to guide and to inspire future advances in synthetic organic chemistry for this kind of polycyclic compounds.

\section{Acknowledgements}

The thank Cynthia M. C. P. Manso for reviewing the text.

\section{Funding}

The authors thank Fundação de Amparo à Pesquisa do Estado de São Paulo (FAPESP, grant 2018/24680-4) and Coordenação de Aperfeiçoamento de Pessoal de Nível Superior (CAPES) Finance Code 001 for financial support and fellowships.

\section{ORCID ${ }^{\circledR}$ iDs}

Giovanni S. Baviera - https://orcid.org/0000-0002-7723-3780

Paulo M. Donate - https://orcid.org/0000-0002-1404-5328

\section{References}

1. Becker, H. D. Chem. Rev. 1993, 93, 145-172. doi:10.1021/cr00017a008

2. Ihmels, H.; Meiswinkel, A.; Mohrschladt, C. J. Org. Lett. 2000, 2, 2865-2867. doi:10.1021/ol006291y

3. Abou-Hatab, S.; Spata, V. A.; Matsika, S. J. Phys. Chem. A 2017, 121, 1213-1222. doi:10.1021/acs.jpca.6b12031

4. Pozzo, J.-L.; Desvergne, J.-P.; Clavier, G. M.; Bouas-Laurent, H.; Jones, P. G.; Perlstein, J. J. Chem. Soc., Perkin Trans. 2 2001, 824-826. doi:10.1039/b008084p

5. Huang, J.; Su, J.-H.; Tian, H. J. Mater. Chem. 2012, 22, 10977-10989. doi:10.1039/c2jm16855c

6. Chen, M.; Yan, L.; Zhao, Y.; Murtaza, I.; Meng, H.; Huang, W. J. Mater. Chem. C 2018, 6, 7416-7444. doi:10.1039/c8tc01865k

7. Van Damme, J.; Du Prez, F. Prog. Polym. Sci. 2018, 82, 92-119. doi:10.1016/j.progpolymsci.2018.02.002

8. Fang, Y.; Du, X.; Du, Z.; Wang, H.; Cheng, X. J. Mater. Chem. A 2017, 5, 8010-8017. doi:10.1039/c7ta00871f

9. Kivrak, A.; Er, Ö. F.; Kivrak, H.; Topal, Y.; Kuş, M.; Çamlısoy, Y. Opt. Mater. (Amsterdam, Neth.) 2017, 73, 206-212. doi:10.1016/j.optmat.2017.08.014

10. Zhao, Y.; Yan, L.; Murtaza, I.; Liang, X.; Meng, H.; Huang, W. Org. Electron. 2017, 43, 105-111. doi:10.1016/j.orgel.2017.01.005 
11. Ho, M.-H.; Wu, Y.-S.; Wen, S.-W.; Chen, T.-M.; Chen, C. H. Appl. Phys. Lett. 2007, 91, 083515. doi:10.1063/1.2773962

12. Wu, C.-L.; Chang, C.-H.; Chang, Y.-T.; Chen, C.-T.; Chen, C.-T.; Su, C.-J. J. Mater. Chem. C 2014, 2, 7188-7200. doi:10.1039/c4tc00876f

13. Okumoto, K.; Kanno, H.; Hamaa, Y.; Takahashi, H.; Shibata, K. Appl. Phys. Lett. 2006, 89, 063504. doi:10.1063/1.2266452

14. Ito, K.; Suzuki, T.; Sakamoto, Y.; Kubota, D.; Inoue, Y.; Sato, F.; Tokito, S. Angew. Chem., Int. Ed. 2003, 42, 1159-1162. doi:10.1002/anie.200390305

15. Kouam, S. F.; Yapna, D. B.; Krohn, K.; Ngadjui, B. T.; Ngoupayo, J.; Choudhary, M. I.; Schulz, B. J. Nat. Prod. 2007, 70, 600-603. doi:10.1021/np060556l

16. Corrêa, T. A.; Alves, C. C. S.; Castro, S. B. R.; Oliveira, E. E.; Franco, L. S.; Ferreira, A. P.; de Almeida, M. V. Chem. Biol. Drug Des. 2013, 82, 463-467. doi:10.1111/cbdd.12183

17. Prakash, G. K. S.; Panja, C.; Shakhmin, A.; Shah, E.; Mathew, T.; Olah, G. A. J. Org. Chem. 2009, 74, 8659-8668. doi:10.1021/jo901668

18. Fieser, L. F. Org. React. 2011, 129-154. doi:10.1002/0471264180.or001.06

19. Li, G.; Zhou, S.; Su, G.; Liu, Y.; Wang, P. G. J. Org. Chem. 2007, 72, 9830-9833. doi:10.1021/jo7017334

20. Bradsher, C. K. Chem. Rev. 1946, 38, 447-499. doi:10.1021/cr60121a003

21. Bradsher, C. K. Chem. Rev. 1987, 87, 1277-1297. doi:10.1021/cr00082a001

22. Bradsher, C. K. J. Am. Chem. Soc. 1940, 62, 486-488. doi:10.1021/ja01860a006

23. Yamato, T.; Sakaue, N.; Shinoda, N.; Matsuo, K. J. Chem. Soc., Perkin Trans. 1 1997, 1193-1200. doi:10.1039/a606205i

24. Yasukawa, T.; Satoh, T.; Miura, M.; Nomura, M. J. Am. Chem. Soc. 2002, 124, 12680-12681. doi:10.1021/ja0280269

25. Huang, W.; Zhou, X.; Kanno, K.-i.; Takahashi, T. Org. Lett. 2004, 6, 2429-2431. doi:10.1021/ol049176m

26. Barluenga, J.; Martínez, S.; Suárez-Sobrino, A. L.; Tomás, M. Org. Lett. 2008, 10, 677-679. doi:10.1021/ol703037q

27. House, H. O.; Koepsell, D. G.; Campbell, W. J. J. Org. Chem. 1972, 37, 1003-1011. doi:10.1021/jo00972a017

28. Koike, T.; Tanabe, M.; Takeuchi, N.; Tobinaga, S. Chem. Pharm. Bull. 1997, 45, 243-248. doi:10.1248/cpb.45.243

29. Rodríguez, D.; Castedo, L.; Domínguez, D.; Saá, C. Org. Lett. 2003, 5 , 3119-3121. doi:10.1021/ol035168e

30. Harvey, R. G.; Cortez, C.; Jacobs, S. A. J. Org. Chem. 1982, 47, 2120-2125. doi:10.1021/jo00132a026

31. Platt, K. L.; Setiabudi, F. J. Chem. Soc., Perkin Trans. 1 1992, 2005-2009. doi:10.1039/p19920002005

32. Harrowven, D. C.; Nunn, M. I. T.; Fenwick, D. R. Tetrahedron Lett. 2002, 43, 7345-7347. doi:10.1016/s0040-4039(02)01720-3

33. Bonifacio, M. C.; Robertson, C. R.; Jung, J.-Y.; King, B. T. J. Org. Chem. 2005, 70, 8522-8526. doi:10.1021/jo0514180

34. Fukutani, T.; Hirano, K.; Satoh, T.; Miura, M. Org. Lett. 2009, 11, 5198-5201. doi:10.1021/ol9021172

35. Zhang, X.; Yu, X.; Ji, D.; Yamamoto, Y.; Almansour, A. I.; Arumugam, N.; Kumar, R. S.; Bao, M. Org. Lett. 2016, 18, 4246-4249. doi:10.1021/acs.orglett.6b01991

36. Shu, C.; Chen, C.-B.; Chen, W.-X.; Ye, L.-W. Org. Lett. 2013, 15, 5542-5545. doi:10.1021/01402713g

37. Park, J.; Choi, H.; Lee, D.-C.; Lee, K. Tetrahedron Lett. 2015, 56 , 7005-7007. doi:10.1016/j.tetlet.2015.10.111
38. Zou, Y.; Young, D. D.; Cruz-Montanez, A.; Deiters, A. Org. Lett. 2008, 10, 4661-4664. doi:10.1021/ol8019549

39. Hoffmann, H.; Mukanov, D.; Ganschow, M.; Rominger, F.; Freudenberg, J.; Bunz, U. H. F. J. Org. Chem. 2019, 84, 9826-9834. doi:10.1021/acs.joc.9b01567

40. Saino, N.; Kawaji, T.; Ito, T.; Matsushita, Y.; Okamoto, S. Tetrahedron Lett. 2010, 51, 1313-1316. doi:10.1016/j.tetlet.2009.12.130

41. Kim, K.; Vasu, D.; Im, H.; Hong, S. Angew. Chem., Int. Ed. 2016, 55, 8652-8655. doi:10.1002/anie.201603661

42. Park, H.; Yoo, K.; Jung, B.; Kim, M. Tetrahedron 2018, 74, 2048-2055. doi:10.1016/j.tet.2018.03.006

43. Kodomari, M.; Nagamatsu, M.; Akaike, M.; Aoyama, T. Tetrahedron Lett. 2008, 49, 2537-2540. doi:10.1016/j.tetlet.2008.02.117

44. Mohammadiannejad-Abbasabadi, K.; Mohammadpoor-Baltork, I.; Tangestaninejad, S.; Moghadam, M.; Mirkhani, V.; Kia, R. Tetrahedron 2016, 72, 1433-1439. doi:10.1016/j.tet.2016.01.041

45. Bhowmik, P. K.; Nedeltchev, A. K.; Han, H. Mol. Cryst. Liq. Cryst. 2009, 501, 125-137. doi:10.1080/15421400802697707

46. Yucel, B.; Meral, K.; Ekinci, D.; Uzunoğlu, G. Y.; Tüzün, N. Ş.; Özbey, S.; Kazak, C.; Ozdemir, Y.; Sanli, B.; Kayık, G.; Dağdeviren, M. Dyes Pigm. 2014, 100, 104-117. doi:10.1016/j.dyepig.2013.08.024

47. Agarwal, N.; Patil, M.; Patil, M. RSC Adv. 2015, 5, 98447-98455. doi:10.1039/c5ra19564k

48. De, J.; Setia, S.; Pal, S. K. ChemistrySelect 2016, 1, 5075-5082. doi:10.1002/slct.201600717

49. Glöcklhofer, F.; Lunzer, M.; Stöger, B.; Fröhlich, J. Chem. - Eur. J. 2016, 22, 5173-5180. doi:10.1002/chem.201600004

50. Škalamera, Đ.; Veljković, J.; Ptiček, L.; Sambol, M.; Mlinarić-Majerski, K.; Basarić, N. Tetrahedron 2017, 73, 5892-5899. doi:10.1016/j.tet.2017.08.038

51. Kuninobu, Y.; Tatsuzaki, T.; Matsuki, T.; Takai, K. J. Org. Chem. 2011, 76, 7005-7009. doi:10.1021/j0200861s

52. Bodzioch, A.; Marciniak, B.; Różycka-Sokołowska, E.; Jeszka, J. K.; Uznański, P.; Kania, S.; Kuliński, J.; Bałczewski, P. Chem. - Eur. J. 2012, 18, 4866-4876. doi:10.1002/chem.201101909

53. Sivasakthikumaran, R.; Nandakumar, M.; Mohanakrishnan, A. K. J. Org. Chem. 2012, 77, 9053-9071. doi:10.1021/jo301410w

54. Sivasakthikumaran, R.; Rafiq, S. M.; Sankar, E.; Clement, J. A.; Mohanakrishnan, A. K. Eur. J. Org. Chem. 2015, 7816-7835. doi:10.1002/ejoc.201501087

55. Rafiq, S. M.; Sivasakthikumaran, R.; Karunakaran, J.; Mohanakrishnan, A. K. Eur. J. Org. Chem. 2015, 5099-5114. doi:10.1002/ejoc.201500493

56. Meindl, B.; Pfennigbauer, K.; Stöger, B.; Heeney, M.; Glöcklhofer, F. J. Org. Chem. 2020, 85, 8240-8244. doi:10.1021/acs.joc.0c00826

57. Lin, C.-H.; Lin, K.-H.; Pal, B.; Tsou, L.-D. Chem. Commun. 2009, 803-805. doi:10.1039/b814840f

58. Ishibashi, J. S. A.; Marshall, J. L.; Mazière, A.; Lovinger, G. J.; Li, B.; Zakharov, L. N.; Dargelos, A.; Graciaa, A.; Chrostowska, A.; Liu, S.-Y. J. Am. Chem. Soc. 2014, 136, 15414-15421. doi:10.1021/ja508813v

59. Link, A.; Fischer, C.; Sparr, C. Synthesis 2017, 49, 397-402. doi:10.1055/s-0036-1588087

60. Ren, Z.-H.; Guan, Z.-H.; Liang, Y.-M. J. Org. Chem. 2009, 74, 3145-3147. doi:10.1021/jo802712n

61. Kitazawa, K.; Kochi, T.; Nitani, M.; le, Y.; Aso, Y.; Kakiuchi, F. Chem. Lett. 2011, 40, 300-302. doi:10.1246/cl.2011.300

62. Umeda, R.; Miyake, S.; Nishiyama, Y. Chem. Lett. 2012, 41, 215-217. doi:10.1246/cl.2012.215 
63. Nakae, T.; Ohnishi, R.; Kitahata, Y.; Soukawa, T.; Sato, H.; Mori, S.; Okujima, T.; Uno, H.; Sakaguchi, H. Tetrahedron Lett. 2012, 53 , 1617-1619. doi:10.1016/j.tetlet.2012.01.071

64. Chan, J. M. W.; Tischler, J. R.; Kooi, S. E.; Bulović, V.; Swager, T. M. J. Am. Chem. Soc. 2009, 131, 5659-5666. doi:10.1021/ja900382r

65. Toyoshima, T.; Yoshida, S.; Watanabe, S. Tetrahedron 2013, 69 , 1904-1911. doi:10.1016/j.tet.2012.12.048

66. Psutka, K. M.; Williams, J.; Paquette, J. A.; Calderon, O.; Bozek, K. J. A.; Williams, V. E.; Maly, K. E. Eur. J. Org. Chem. 2015, 1456-1463. doi:10.1002/ejoc.201403504

67. Johnson, M. M.; Ngwira, K. J.; Rousseau, A. L.; Lemmerer, A.; de Koning, C. B. Tetrahedron 2018, 74, 12-18. doi:10.1016/j.tet.2017.11.023

68. Srivastava, M.; Singh, J.; Singh, S. B.; Tiwari, K.; Pathak, V. K.; Singh, J. Green Chem. 2012, 14, 901-905. doi:10.1039/c2gc16425f

69. Mannes, P. Z.; Onyango, E. O.; Gribble, G. W. J. Org. Chem. 2015, 80, 11189-11192. doi:10.1021/acs.joc.5b01972

70. Pünner, F.; Schieven, J.; Hilt, G. Org. Lett. 2013, 15, 4888-4891. doi:10.1021/ol4023276

71. Serevičius, T.; Komskis, R.; Adomènas, P.; Adomènienè, O.; Jankauskas, V.; Gruodis, A.; Kazlauskas, K.; Juršènas, S. Phys. Chem. Chem. Phys. 2014, 16, 7089-7101. doi:10.1039/c4cp00236a

72. Suchand, B.; Satyanarayana, G. Synthesis 2019, 51, 769-779. doi:10.1055/s-0037-1610296

73. Li, Y.-J.; Huang, H.-M.; Ye, Q.; Hou, L.-F.; Yu, W.-B.; Jia, J.-H.; Gao, J.-R. Adv. Synth. Catal. 2014, 356, 421-427. doi:10.1002/adsc.201300892

74. Somai Magar, K. B.; Xia, L.; Lee, Y. R. Chem. Commun. 2015, 51, 8592-8595. doi:10.1039/c5cc00623f

75. Sawano, T.; Toyoshima, Y.; Takeuchi, R. Inorganics 2019, 7, 138. doi:10.3390/inorganics7110138

76. Nandi, G. C.; Samai, S.; Kumar, R.; Singh, M. S. Tetrahedron 2009, 65, 7129-7134. doi:10.1016/j.tet.2009.06.024

77. Sun, X. J.; Zhou, J. F.; Zhao, P. S. J. Heterocycl. Chem. 2011, 48, 1347-1350. doi:10.1002/jhet.742

78. Sun, X.-J.; Zhou, J.-F.; Zhao, P.-S. Synth. Commun. 2012, 42, 1542-1549. doi:10.1080/00397911.2010.541966

79. Hueso-Falcón, I.; Amesty, Á.; Martín, P.; López-Rodríguez, M.; Fernández-Pérez, L.; Estévez-Braun, A. Tetrahedron 2014, 70 , 8480-8487. doi:10.1016/j.tet.2014.09.076

80. Naeimi, H.; Namdari, R. Dyes Pigm. 2009, 81, 259-263. doi:10.1016/j.dyepig.2008.10.019

81. Kim, K.; Min, M.; Hong, S. Adv. Synth. Catal. 2017, 359, 848-852. doi:10.1002/adsc.201601057

82. Basak, S.; Mal, D. J. Org. Chem. 2017, 82, 11035-11051. doi:10.1021/acs.joc.7b01987

83. Bettinger, H. F.; Einholz, R.; Göttler, A.; Junge, M.; Sättele, M.-S.; Schnepf, A.; Schrenk, C.; Schundelmeier, S.; Speiser, B. Org. Chem. Front. 2017, 4, 853-860. doi:10.1039/c7qo00117g

84. Geiger, T.; Haupt, A.; Maichle-Mössmer, C.; Schrenk, C.; Schnepf, A.; Bettinger, H. F. J. Org. Chem. 2019, 84, 10120-10135. doi:10.1021/acs.joc.9b01317

85. Ueda, Y.; Suzuki, K.; Ohmori, K. Org. Lett. 2020, 22, 2002-2006. doi:10.1021/acs.orglett.0c00354

86. Novak, I. Chem. Phys. Lett. 2021, 763, 138181. doi:10.1016/j.cplett.2020.138181

\section{License and Terms}

This is an Open Access article under the terms of the Creative Commons Attribution License (https://creativecommons.org/licenses/by/4.0). Please note that the reuse, redistribution and reproduction in particular requires that the author(s) and source are credited and that individual graphics may be subject to special legal provisions.

The license is subject to the Beilstein Journal of Organic Chemistry terms and conditions: (https://www.beilstein-journals.org/bjoc/terms)

The definitive version of this article is the electronic one which can be found at: $\underline{\text { https://doi.org/10.3762/bjoc.17.131 }}$ 